\title{
The Perceptions of First-year Students' Writing Needs
}

Lori R. Rosove

A thesis submitted to the Faculty of Graduate Studies and Research in partial fulfillment of the requirement of the degree of Master of Arts in Applied Language Studies

School of Linguistics and Language Studies

Carleton University

September 2009

Copyright (C) Lori R. Rosove, 2009 


$\begin{array}{ll}\begin{array}{l}\text { Library and Archives } \\ \text { Canada }\end{array} & \begin{array}{l}\text { Bibliothèque et } \\ \text { Archives Canada }\end{array} \\ \begin{array}{l}\text { Published Heritage } \\ \text { Branch }\end{array} & \begin{array}{l}\text { Direction du } \\ \text { Patrimoine de l'édition }\end{array} \\ \begin{array}{l}\text { 395 Wellington Street } \\ \text { Ottawa ON K1A ON4 } \\ \text { Canada }\end{array} & \begin{array}{l}\text { 395, rue Wellington } \\ \text { Ottawa ON K1A ON4 } \\ \text { Canada }\end{array}\end{array}$

Your file Votre référence

ISBN: 978-0-494-58430-9

Our file Notre référence

ISBN: $978-0-494-58430-9$

\section{NOTICE:}

The author has granted a nonexclusive license allowing Library and Archives Canada to reproduce, publish, archive, preserve, conserve, communicate to the public by telecommunication or on the Internet, loan, distribute and sell theses worldwide, for commercial or noncommercial purposes, in microform, paper, electronic and/or any other formats.

The author retains copyright ownership and moral rights in this thesis. Neither the thesis nor substantial extracts from it may be printed or otherwise reproduced without the author's permission.
AVIS:

L'auteur a accordé une licence non exclusive permettant à la Bibliothèque et Archives Canada de reproduire, publier, archiver, sauvegarder, conserver, transmettre au public par télécommunication ou par l'Internet, prêter, distribuer et vendre des thèses partout dans le monde, à des fins commerciales ou autres, sur support microforme, papier, électronique et/ou autres formats.

L'auteur conserve la propriété du droit d'auteur et des droits moraux qui protège cette thèse. $\mathrm{Ni}$ la thèse ni des extraits substantiels de celle-ci ne doivent être imprimés ou autrement reproduits sans son autorisation.
In compliance with the Canadian Privacy Act some supporting forms may have been removed from this thesis.

While these forms may be included in the document page count, their removal does not represent any loss of content from the thesis.
Conformément à la loi canadienne sur la protection de la vie privée, quelques formulaires secondaires ont été enlevés de cette thèse.

Bien que ces formulaires aient inclus dans la pagination, il n'y aura aucun contenu manquant.

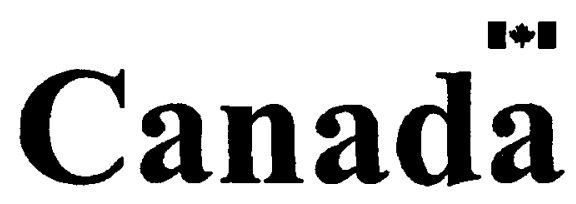




\section{Acknowledgements}

Above all, I want to thank my supervisor, Natasha Artemeva. Without her wisdom, knowledge, and unwavering patience, I would not have succeeded.

Thank you to my endlessly supportive family, particularly Jordan, who did everything and beyond to help me this year.

I would also like to thank my superb teachers of the SLaLS graduate faculty, with whom it's been a privilege to share this past year.

Thank you to the study participants. I appreciate the time you took to share your valuable insights.

Finally, I would like to thank two special women, Katie and Patti, who took interest in my work, listened to my complaints, and cheered me on. 


\begin{abstract}
This study investigates university students' perceptions of first-year academic writing and of what they need to help them to enhance their writing competence. Special attention is paid to the comparison of students' and professors' perceptions of first-year students' writing needs. First and second-year students as well as professors have been interviewed in order to gather data on their perceptions and their responses analyzed from the Grounded Theory perspective. The study has revealed contradictory perceptions of the students and the professors, particularly regarding the importance of writing at university, the value of feedback on students' written assignments, and the type of explicit instruction each group viewed as necessary for students' optimum learning and performance. The findings of the study suggest that a communication gap between professors and students, based on professors' tacit disciplinary knowledge, a lack of contextualized assignments, and the professors' apparent tendency not to accommodate the students' learning needs while in transition from high school to university may be responsible for these contradictory perceptions. In turn, these perceptions appear to affect professors' teaching and student performance in the first-year of university.
\end{abstract}




\section{Table of Contents}

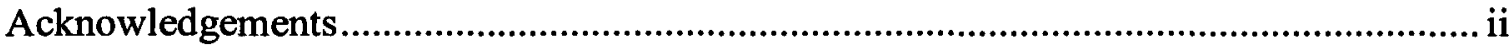

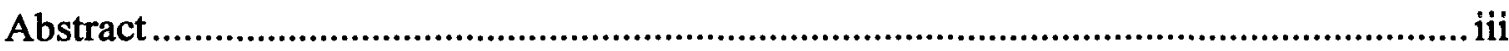

Table of Contents .......................................................................................................... iv

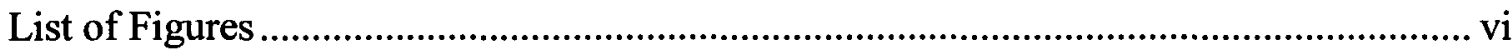

Notations and Abbreviations................................................................................ vii

1. Introduction .......................................................................................................... 1

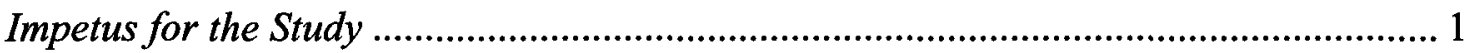

Research Question ......................................................................................................... 3

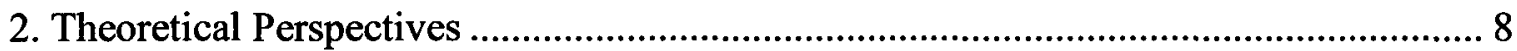

Theoretical Framework ........................................................................................... 8

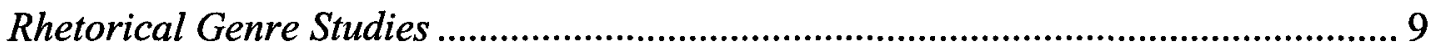

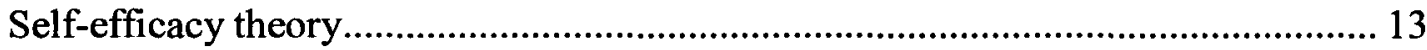

Paradigmatic Shifts in the History of Academic Writing Pedagogy ........................... 18

Research into Academic Writing ............................................................................. 22

Insights for academic pedagogy................................................................................ 22

Research on students' perceptions of their writing needs .......................................... 26

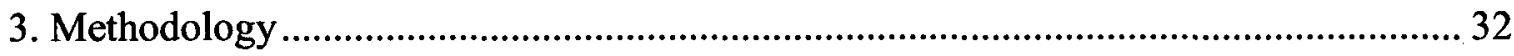

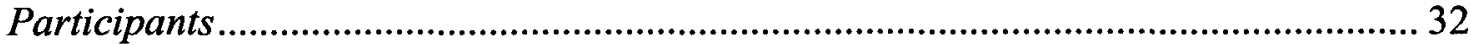

Student participants ........................................................................................... 34

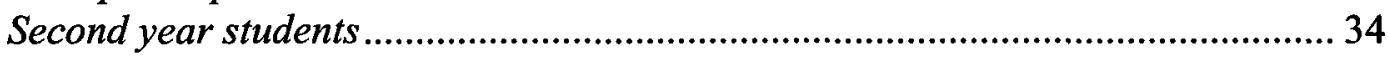

First year students …….................................................................................... 37

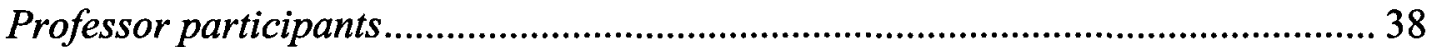

Data

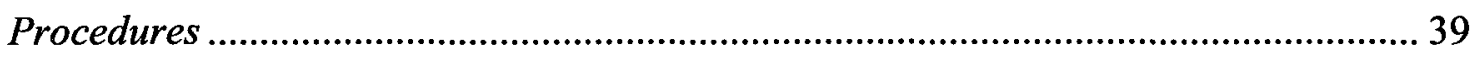

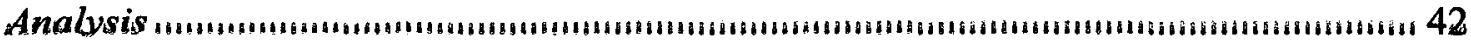

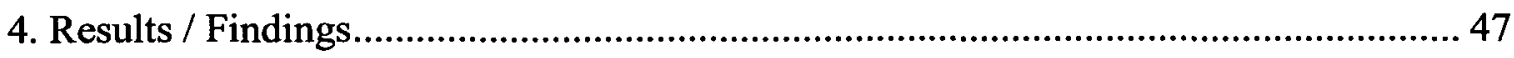

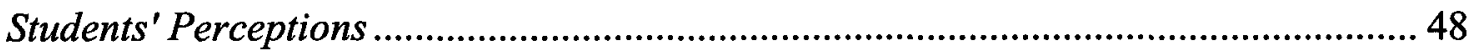

Clear Expectations ............................................................................................... 48

Constructive and Expansive Feedback .................................................................5 50

Meaningful Assignments ........................................................................................ 51

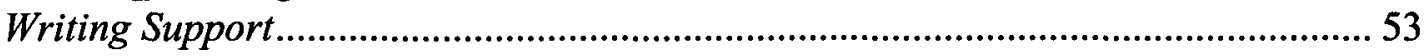

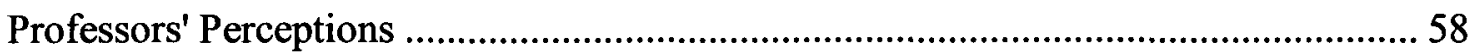


Grammar and Writing Mechanics ........................................................................5 59

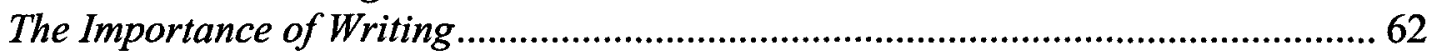

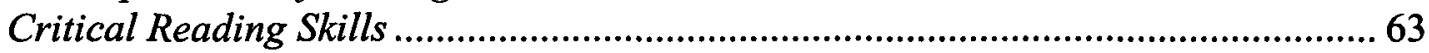

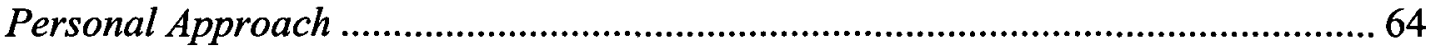

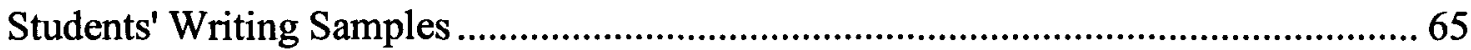

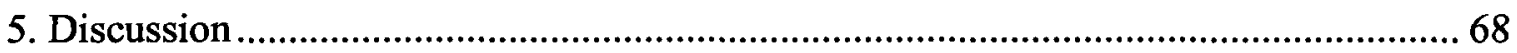

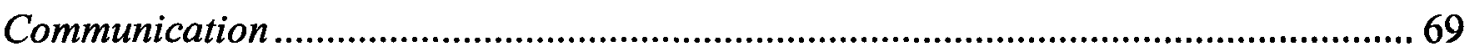

Disciplinary discourse ……………….................................................................... 71

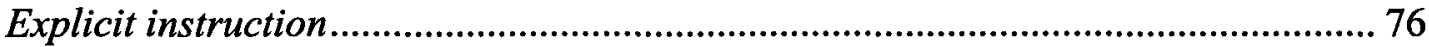

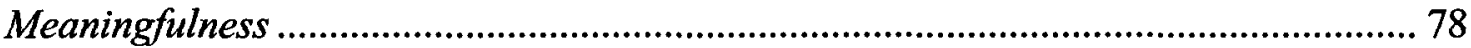

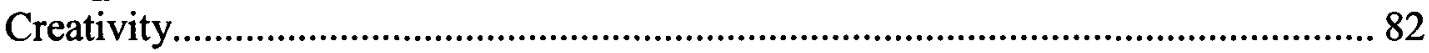

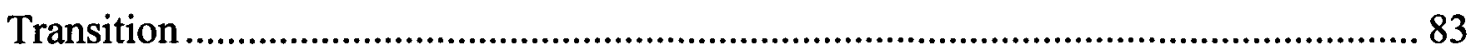

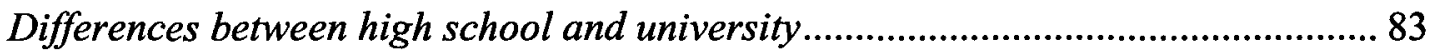

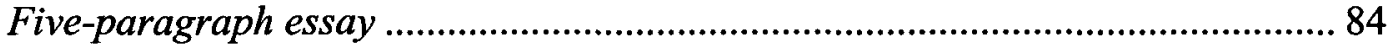

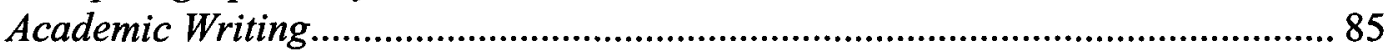

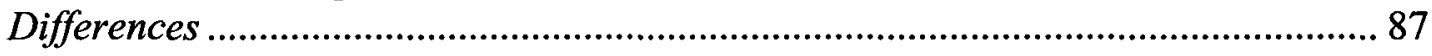

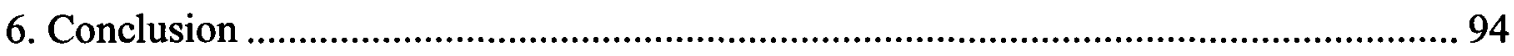

Summary of Research Findings ............................................................................. 95

Limitations and Contributions to the Field............................................................. 100

Directions for Future Research ................................................................................. 101

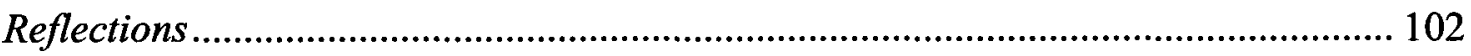

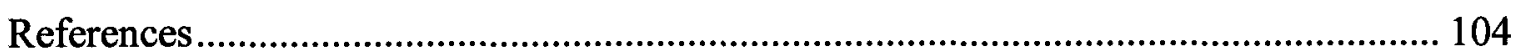

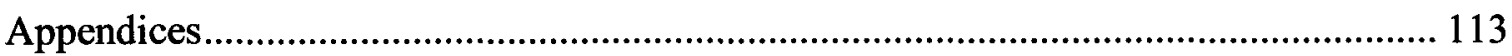

Appendix A: Invterview Questions for Students .................................................... 113

Appendix B: Interview Questions for Professors .................................................... 115

Appendix C: Ethics Approval Certificate .................................................................. 116

Appendix D: DELNA Rating Scale ................................................................... 117

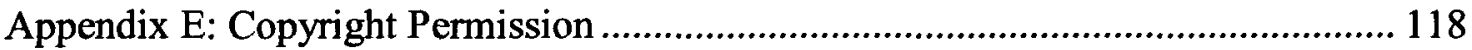

Appendix F: Comparison of Student Papers............................................................ 119

Appendix G: Feedback Styles on Student Papers....................................................... 120 


\section{List of Figures}

Figure 1. Example of labeling phenomena with descriptive codes.................. 43

Figure 2. Conceptual categories............................................ 44

Figure 3. Overarching themes.................................................... 45 


\section{Notations and Abbreviations}

... - indicates missing or deleted text

[ ] - indicates added or changed text for grammatical or explanatory purposes

( ) - indicates changed text that contained identifying information

RGS - Rhetorical Genre Studies

FYE - First-Year Experience 


\section{Introduction}

You know you go into university and it can be a little bit defeating sometimes when you've been viewing yourself as a good student, and getting good grades, and being proud of what you're accomplishing in high school, and then you come to university and your grades are sinking, and you don't understand why, and it just makes you feel a little bit frustrated and defeated because no matter what, you're trying, but the results you used to get you just don't get any more... so . . . yeah. (Alana, March 25, 2009)

I think most people would agree that these words represent the unambiguous feelings of an exasperated student.

\section{Impetus for the Study}

Writing at university can be very challenging for many people, even for those with several years of professional writing experience. I know this because I am one of those people. After having worked in the field of Social Work for many years, where a primary responsibility of mine was to write comprehensive reports that had significant implications for my clientele, I perceived myself as a fairly good writer. But unbeknownst to me, this perception was about to change shortly after returning to university this past year, where I found myself immersed not only in a discipline that I was completely unfamiliar with but also in the greater academic environment, and consequently, academic discourse, that were somewhat foreign to me. I found that I did not possess the repertoire of experiences that was necessary to write competently in this new field and as a result, my earlier perception of myself as a generally effective writer took a down turn. 
In reflecting on this experience, it occurred to me that if I had difficulty adjusting to the requirements of writing at university, then first-year students, with no professional writing experience and limited wisdom gained from past experiences to help them in challenging situations, must have at least the same if not more difficulty with writing at university. In addition to the transition to participating in classrooms of 400 students instead of the 30 that they were used to in high school and exposure to a teaching style that can be less personal, first-year students are often given more complex and longer writing assignments than in high school, and the professors' expectations of student writing are usually quite different from what they experienced previously. Writing long and complex essays in their university classes can lead to a lot of stress for students because, first of all, as Bereiter and Scardamalia (1983) acknowledge, "writing a long essay is probably the most complex constructive act that most human beings are ever expected to perform" (p.20) and yet, secondly, as Paré (2007) explained, this complex writing is central to students' academic experience where the expectation is for them to "produce finished and, ideally, polished texts" (p.4). This expectation for first-year students might not always appear reasonable considering that the students are novices to the university environment and thus have either not had any or had only a limited exposure to academic writing styles. Nevertheless, this expectation does exist, and it is exactly this quandary in combination with my curiosity about students' perceptions of their writing needs that lead to this study.

My curiosity about students' writing needs began while I was working as a writing tutor at a Canadian university writing centre, where I encountered many students, particularly first-year students, who struggled with their assignments. For example, as it 
came out in one-on-one tutoring sessions, they often did not understand the assignment sheets, were uncertain about how to begin writing, and presented their written ideas in a disconnected fashion. I wondered if these writing issues were representative of the greater student body of first-year students or if these issues, in fact, were particular only to the relatively small number of students who sought out services at the writing centre. My hunch was that more than a small number of first-year students struggled with writing at university and this uncertainty served as an impetus for this study.

\section{Research Question}

Later, as I immersed myself in Writing Studies and encountered the ongoing scholarly conversation about teaching academic writing (e.g., Devitt, 2004; Fahnestock, 1993; Freedman, 1993; Swales, 1990; Williams \& Colomb, 1993), I perceived that this conversation not only reflected the importance of writing in the academic institution but also revealed an urgency to focus on the significant challenges that academic writing seemed to present for a majority of students. For this reason, I began to gain more certainty regarding my hunch that writing at university proposed a significant challenge for many students.

The above mentioned conversation about teaching academic writing was initiated by Freedman in 1993 when she asserted her position on teaching students written genres: "Genres are responses to contexts [and therefore] can [not] be learned out of context by explicating features and specifying rules of their form or context” (p.225). A response from Williams and Colomb repudiated Freedman's claim with their insistence that "substantial bodies of research [had] found that effective teaching includes both explicit and inexplicit strategies" (p.257). Fahnestock challenged Freedman's position that rules 
for content and form do not help students to understand genres when she referred to classical rhetorical education as having been a successful way of teaching genre not "in a way that specifies every sentence-level feature, ... instead ... by what they (genres) try to accomplish ... to learn a genre, ... was to learn its options" (pp. 267-268). More recently Devitt (2004) supported Fahnestock's notion of explicitly learning about the purpose of a genre and targeted the teaching of written genres, yet from a different angle, as she set forth the need to teach "genre awareness" as a pedagogy that would help students to write more effectively. She claimed that in order for students to become aware of the rhetorical purposes of and ideologies behind a genre, they must learn how to "discern [a genre]" (p.195).

Based on the controversial and inconclusive nature of this conversation, it seemed that more scholars might continue to add their opinions about effective ways for students to learn to write at university. Although these opinions may be helpful, the discussion still remains mostly theoretical. The groups that have been missing from this conversation, whose perceptions, attitudes, expectations, and beliefs about academic writing would provide the most practical sources of relevant information to this conversation, are the students and their instructors.

Pajares and Valiante (2006) validated the importance of students' perceptions for their learning experiences by saying that "students' beliefs about their own writing processes and competence are instrumental to their ultimate success as writers" (p.158). This assertion is based on the premise of self-efficacy theory (e.g., Bandura, 1977, 1986, 1997; Pajares, 2002; Pintrich, 1999; Schunk, 2003) which purports that an individual's beliefs about her ability to attain a goal, concerning a specific skill or ability, influences 
the individual's ability to do so. Although I fully recognize that students' perceptions of what they need in order to help them increase their writing competence may not be necessarily indicative of what they actually need, I believe it is important to listen to what the students are saying as they, the participants in the pedagogies, are able to share insight into the effectiveness of what is being delivered to them.

I designed the study presented in this thesis in order to a) explore the writing needs of first-year students as perceived by these students a year later, when they are already second-year university students and b) analyze samples of their writing in order to examine if there were changes in their writing as the students progressed through their academic studies and gained some disciplinary knowledge in different subjects. In addition to the students' perceptions, I intended to investigate the professors' perceptions about the students' writing needs in order to see if the perceptions of students and professors were similar. The importance of students and professors having similar perceptions and, therefore, expectations of academic writing, became apparent to me during my experience as a writing tutor, when I learned of the frustrations that students felt about their writing assignments and that professors experienced regarding the students' difficulties with writing. For example, one of the professors expressed a common hustration by sayng, "I am matking these stutents" papers and thoy have fio idea how to write! How did they ever get into university?"

I believe there is much to be learned from listening to both students' and professors' voices and comparing their perceptions. Gaining the understanding of both groups' perceptions of first-year students' academic writing needs will add to the already assembled body of knowledge in the area of academic writing studies and assist us not 
only in gaining a deeper understanding of the dynamics of first-year students' learning but also in developing and administering writing support programs. Therefore, the purpose of this study is to search for answers to the following research question:

What are the academic writing needs of first-year students as perceived by first and second-year students and their professors?

In investigating the research question, I designed the study that is presented and discussed in the following chapters. Chapter 1 addresses the importance of writing at university, reveals the difficulties that students--primarily first-year students--have with this, proposes the importance of collecting and understanding students' and their professors' perceptions on students' writing needs in first-year university, and introduces the theoretical framework for the study. In order to develop a better understanding of the research question, I use the theoretical framework of Rhetorical Genre Studies (RGS) (e.g., Artemeva, 2005; Devitt, 2004; Freedman, 1993; Freedman \& Medway, 1994; Dias, Freedman, Medway, \& Paré 1999; Miller, 1984; Paré, 1994, 2007) and self-efficacy theory (e.g., Bandura, 1977,1986,1997, 2001; Pajares, 2002; Pajares, \& Schunk, 2001, 2005; Pintrich, 1999; Schunk, 2003). In chapter 2, I discuss the theoretical framework for this study, provide a brief overview of the paradigmatic shifts in the history of academic writing pedagogy, and identify and discuss significant pedagogical insights in the domain of academic writing studies that are directly relevant to my research. In chapter 3, I present the methodology used in the study including sections on participants, data, procedure, and analysis, and in chapter 4 , the results of the data analysis. Chapter 5 contains a discussion of the findings of the study, and finally, in chapter 6 , I present the 
conclusion of the study, which includes a summary of the research findings, limitations of the study, and directions for future research. 


\section{Theoretical Perspectives}

In this section, I begin with a discussion of the theoretical framework for this study, Rhetorical Genre Studies and self-efficacy theory, which are used in this thesis to interpret the research data. Following this discussion, I provide an overview of the paradigmatic shifts in the history of academic writing pedagogy. Gaining an understanding of the causes of these shifts may help us to better understand students' perceptions of the challenges of university writing, and through this new, deeper understanding we may discover what is actually taught in classes if and when professors address students' needs and how effective this teaching is. I then report on and discuss research in academic writing that is directly relevant to my study as it helps me to understand the origins of students' perceptions of their writing needs. In the subsections that follow, I discuss pedagogical insights in the domain of academic writing studies and research on students' perceptions of their writing needs.

\section{Theoretical Framework}

In considering further factors that influence students' receptiveness to learning, it may be helpful to look at the ways that writing at university can be understood in terms of its genres in order "for researchers, teachers, and scholars to cast some light on what is actually going on when we participate in the use of written genres" (Freedman \& Medway, 1994, p.4). In additlon, it is worth our whilo to consider the of foot of students" perceptions of their ability to complete assignments. For these purposes, I have chosen the theoretical framework of Rhetorical Genre Studies and self-efficacy theory from which to view and gain a better understanding of the outcomes of this study. 


\section{Rhetorical Genre Studies}

Writing is a key academic activity (Paré, 2007) and, according to Freedman and Medway (1994), is "increasingly being understood as a way of responding to a specific reader (or readers) within a specific context on a specific occasion" (p.5). Miller (1984), in her seminal article "Genre as Social Action", provided the original theoretical substance to that assertion by establishing the main tenet of RGS: "A rhetorically sound definition of genre must be centered not on the substance or the form of discourse but on the action it is used to accomplish" (p.151). She explained that genres cannot be classified the way forms can, as they "change, evolve, [and] decay, and [because of this,] the number of genres current in any society is indeterminate" (p.163). It is precisely the understanding of genre as meaningful action that can influence how academic writing is presented to and perceived by students, as it provides teachers with a perspective from which to introduce and involve students in the disciplinary discourse of their classroom. To provide a further understanding of RGS and how it relates to students' perceptions of their writing needs at university, some of its key concepts are highlighted below.

If we agree with Miller that genre is social action, then written expression of genres is a social activity ${ }^{1}$. Freedman and Medway (1994) commented that "scholars have been recognizing that writing is social in the sense that, whether others are present [such as in peer collaboration] or not, the writer constantly draws on previous interaction with others during their composing" (p.5).

Further to the development of the notion of the social interaction of genres, Bakhtin (1986) provided us with the concept of addressivity; that is, the concept that all

\footnotetext{
'Please note that when the words "action" and "activity" are used in this thesis, they are not assigned the meanings that these terms possess in Activity Theory.
} 
writing is addressed to someone and therefore anticipates a response. This concept allows professors and students to view the connection between texts and how the students' writing inherently provides a response and demands an audience. Quite relevant for university professors, Bakhtin also asserted that, "genres must be fully mastered in order to be manipulated freely" (p.80). Thus, students who are unfamiliar with the disciplinary genres will take some time before they are able to write comfortably within the particular discipline, adhering to the particular conventions of the disciplinary discourse.

Since genres are social actions, they must then exist in a social environment, which RGS scholars refer to as situation. Dias, Freedman, Medway, and Paré (1999) viewed situation as "a shared, communally available, culturally defined reality" (p.18) and asserted that "all writing is a response to ... an interpretation of a situation, because what determines the writing is less the objective state of affairs than the writer's understanding of it" (pp.17, 18). Therefore, in order for students to perceive meaningfulness in their university writing assignments, these must exist within a particular context that the students find relevant. Within a context, part of what is shared is a discourse, which is the written or verbal language--such as the "abbreviations, acronyms, argots, and other special terms"--that is used within a particular group (Swales, 1998, p.20) and that represent an understanding of specific knowledge. Swales referred to the groups that employ these discourses as discourse communities and explained that they are formed based on "what people do, rather than in who they are" (p.20). Therefore, a group of students who are highly immersed in an advanced level of study, such as medical students, can be viewed as a discourse community through their use of genres in writing, reading, and speaking because, as Miller (1984) observed, 
"genres serve as keys to understanding how to participate in the actions of a community" (p.165).

Discourse communities, such as the medical students exemplified above, have a socially recognized purpose, which RGS refers to as exigence. More specifically, Miller (1984), drawing on Bitzer's work, defined exigence as “a form of social knowledge--a mutually construing of objects, events, interests, and purposes that not only links them but also makes them what they are: an objectified social need" (p.157). For example, if universities set admission standards too high, fewer students will be able to gain a university education and, because our society values education, there would be an exigence to lower the admission standards. This exigence would lead to a forum for discussing the ways to accomplish the task, which would employ specific genres for doing so.

Behind the exigence is a social motive. Dias et al. (1999) explained social motive as "a motive that is socially recognized and allowed for" (p.20), which is different from a rhetor's intention--an individual's motive in response to the social situation--or a motive that is shared by a group. They added that social motives and the genres that embody these are both enabling and constraining as they can provide a mode for expressing support for the exigence but can also limit how this support is to be expressed. For example, if a university admininstrator does not feel it is in the best interests of the university to lower the admission standards, but understands that it is considered to be in the best interests of society to do so, the administrator would likely be bound by the social motive to increase enrollment. While her personal opinion was being constrained, 
the adherence to the social motive was enabling more of society to participate in a socially valued activity--a university education.

This review of some of the key concepts of RGS provides us with a starting point from which to view students' writing at university and the formation of their perceptions of it, as it forces us to be aware of the social context that we are communicating in and responding to, reminding us that this social context is always present. Therefore trying to have students write as if the social context is not present or as if the social context were completely different from the real classroom context that students experience may only be confusing for students and will most likely lack meaning for them. An example of professors not recognizing the classroom as the social context that it is, is when they give assignments situated in simulated contexts, where the students are expected to respond in the capacity of the assigned imagined role. The reality is that the students know that this is not a real situation and their writing will more likely reflect the social context of the classroom, where they are trying to meet their professor's expectations and get the best mark they can (cf. Dias et al., 1999). Lave and Wenger (1991) reinforced the classroom as a valid social context: "Schools themselves as social institutions and as places of learning constitute very specific contexts" ( $p .40)$ that need to be acknowledged by professors in their course design.

RGS provides an understanding of genres as ways in which to express belonging in a particular community and to present meaningful communication in society. RGS reveals that it may be easy to learn the gross features of genre-structure and style, but a challenge to comprehend the audience, purpose, values, and expectations that form a genre. Freedman (1993) reflected this idea in her statement that "exposure to written 
discourse and immersion in the relevant contexts are both necessary, although not sufficient, conditions for acquiring new genres" and added that "affective factors such as degree of anxiety or motivation, as well as learning styles, play a role" (p.247). The fact that RGS does not account for such affective factors, and in particular, for motivational factors, which are relevant in acquiring new genres, leaves one to search for another theory in order to gain a better understanding of how motivation leads to genre acquisition and thus, to meaningful learning. For this reason I turn to self-efficacy theory to help me account for motivational factors that contribute to students acquiring new genres that they use in their writing at university.

Self-efficacy theory

Self-efficacy theory has been developed within the larger framework of social cognitive theory. Social cognitive theory views humans as actively involved in their own development and achievement. According to Bandura (1986), founder of social cognitive theory, a key component of this theory is an ongoing inter-face between personal beliefs and the environment that determines human behaviour. Bandura (1997) explained that the most significant of personal beliefs that affect human functioning are self-efficacy beliefs, which he defined as "beliefs in one's capabilities to organize and execute the courses of action required to produce given attainments" (p.3). The faet that alfaefficiacy theory focuses on an individual's judgement of her ability to achieve specific tasks or acquire specific skills makes it different than other self-belief theories which focus on an individual's judgement of certain characteristics or general ability she may have. Furthermore, Bandura (1977) asserted that the main contention of self-efficacy theory is that an individual's motivation is dictated more by what she believes than by what she 
knows is true and,thus, how people behave can be better predicted by the beliefs they hold about their capabilities than by what they are actually capable of accomplishing. Although it does not seem likely that beliefs can produce success when required abilities and knowledge are absent, it is self-efficacy perceptions that help determine how well knowledge and skills are acquired and, then, what the individual does with them. Therefore, the understanding of self-efficacy theory is highly relevant to teaching as it informs us of the potential for students' knowledge acquisition to be influenced by their perception of their ability to competently complete a particular assignment. To provide a further understanding of self-efficacy theory and how it relates to students' perceptions of their writing needs at university, some of the key concepts are highlighted below.

First, self-efficacy beliefs determine the effort that individuals exert and, further, how long they may persist at a given task, despite challenges they are facing regarding the accomplishment of that task (Bandura, 1977, 2001). An example of this might be a student who believes that she can write an " $A$ " final paper despite writing several " $C$ " papers during the term and continually revises the paper in the belief that eventually the paper will be an "A." It is possible that the ongoing revisions (if, for example, they are based on constructive feedback) might lead the student to produce an "A" paper. Furthermore, there is a cyclical nature in the effort that individuals exert towards accomplishing a given task. That is, individuals perceive their competence concerning a particular activity based on the results from a previous effort that was exerted for a similar activity, which influences their self-efficacy for future similar tasks (Pajares \& Valiante, 2006). A professor might see this cycle occurring with students who complete 
an assignment, and then, based on the students' perceptions of their achievement on the assignment, develop either high or low efficacy beliefs for future similar assignments.

The above example illustrates the subjective nature of goal attainment, a second key concept of self-efficacy theory. Linnenbrink and Pintrich (2003) explained this concept as follows: "The goal may be determined by the individual, task conditions, or environment ... [and therefore] self-efficacy judgements for similar tasks may vary as a function of intraindividual or environmental differences" (p.122). An example of an environmental difference may be the case of a student who, despite having written competent assignments in the past, might have lower than usual self-efficacy because he has a new class with a teacher who has a reputation for giving difficult assignments.

Goal attainment is what differentiates self-efficacy beliefs from other influential beliefs on motivation, such as self-concept. The definition of self-efficacy beliefs, as noted earlier in this section, focuses on a belief in one's ability to attain specific goals, whereas self-concept beliefs are seen to be related to perceptions about one's self-worth. These two beliefs independently affect motivation (Pajares \& Schunk, 2005; Skaalvik, 1997) and are influenced by subjective factors, as I mentioned above when describing goal attainment. For example, a student may feel confident about completing a particular writing assignment but does not feel that she is a good writer. The student's low selfconcept belief does not have a negative impact on her self-efficacy beliefs because this task does not necessarily mean a lot to her, thus, her motivation for goal attainment supercedes her self-concept beliefs (Pajares \& Schunk, 2001, 2005). It may be helpful for professors to be able to differentiate between self-efficacy and self-concept beliefs for 
the purpose of gaining a better understanding of what is affecting their students' motivation to attain goals, at a particular point in time.

Regarding motivation, a third key concept of self-efficacy theory, there are three relevant aspects of it that affect student self-efficacy and ultimately have an effect on learning and achievement: personal interest in the content or task, perceived utility of the content or task, and perceived importance about the content or task. Not all three aspects have to be viewed positively in order for self-efficacy to be high because one aspect can carry more weight than the others, which can provide for sufficient motivation to accomplish the task (Linnenbrink \& Pintrich, 2003). An example might be of university students who are not particularly interested in accounting, but view it as important for them to learn being that they are pursuing a degree in Commerce.

In understanding motivation further, one could observe the reciprocal relationship between self-efficacy beliefs and motivation. That is, high self-efficacy beliefs may promote and sustain motivation (Schunk, 2003) and motivation, originating from relevant aspects of interest, utility, and/or importance, as introduced above, increases selfefficacy. Considering this relationship in combination with the direct influence that selfefficacy has on goal attainment, as previously discussed, professors' efforts towards increasing student motivation, which increases self-efficacy, may be critically important for learning.

In addition to the relevant aspects of motivation that have been identified above as having an effect on self-efficacy and, ultimately, on learning, feedback on assignments is seen as influencing student motivation. Pajares and Valiante (2006) noted that "it is usually easier to weaken [students'] self-efficacy beliefs through negative appraisals than 
to strengthen such beliefs through positive encouragement" (p.160). This is significant for professors to be aware of, as it is important for them to understand the powerful influence that the feedback they provide on students' assignments has on these students' self-efficacy beliefs. Perhaps if known, professors may be more conscious about providing constructive, yet still honest, feedback to their students and, more so, may instruct their often inexperienced teaching assistants to do the same.

The premise that negative feedback weakens students' self-efficacy beliefs, as discussed above, may suggest that student motivation may be tied to their emotions, a fourth key concept of self-efficacy theory. Bandura (1977) explained: "By conjuring up fear-provoking thoughts about their ineptitude, individuals can rouse themselves to elevated levels of anxiety that far exceed the fear experienced during the actual threatening situation" (p.199) and, thereby, lower their self-efficacy beliefs. That is, when a student receives negative feedback on an assignment, she may allow this to negatively influence her self-concept by considering herself incapable of completing future assignments, which may result in far more anxiety about future assignments than was initially present when completing the original task.

In conclusion, self-efficacy theory suggests that what students believe about their abilities affects success in their academic endeavors (Pajares \& Valiante, 2006). Although self-efficacy beliefs are individually determined, in reviewing the key concepts of this theory, particularly goal attainment, motivation, and emotion, we see the social influence on self-efficacy beliefs, from professors to students. In reflecting back on the key concepts of RGS, the central RGS concept is that of writing as social activity. Perhaps the acknowledgement of the centrality of the social aspect of self-efficacy theory 
and coupling it with RGS can help us to better understand the many influences that affect university students, their perceptions of their writing needs, and their acquisition of writing competence, and among these influences, the influence of their professors. In order to gain insight regarding some of these influences that affect university students' acquisition of writing competence, we now turn to an overview of the history of academic writing pedagogies.

\section{Paradigmatic Shifts in the History of Academic Writing Pedagogy}

For a long time there have been ongoing changes in writing pedagogy in the English language educational contexts in an attempt to respond to the difficulties that students have been having with developing rhetorical writing competence. Looking back at the history of rhetorical studies, we can see that rhetoric was central in education in Ancient Greece and attracted the interest of such significant thinkers as Plato and Aristotle, although at that time, the focus of rhetorical education was mostly on oral speech rather than writing. By the time of the Renaissance, rhetoric lost its place as the leader in pedagogical instruction as new intellectuals were arguing that invention, the creative aspect of the process of writing, could not be taught within the rigid boundaries of rhetorical theories (Freedman \& Pringle, 1980). This left rhetoric representing only the stylistic aspects of writing, and by the early $20^{\text {th }}$ century, Corbett reported that writing studies focused on little more than "the topic sentence, the various methods of developing the paragraph ... and the holy trinity of unity, coherence, and emphasis" (as cited in Freedman \& Pringle, 1980, p. 174). The focus on product rather than the creative process remained central in the teaching of writing for the first half of the $20^{\text {th }}$ century. As Russell (1992) observed, writing was not thought of as language belonging to the academic 
disciplines but rather as "a set of generalizable, mechanical 'skills' ... that could be taught separate from content, as a mere adjunct or service to a curriculum" (p.25). This perception resulted in a multitude of prescriptive handbooks and texts for teachers to use in their classrooms and in the birth of the traditional first-year composition course at American universities.

Ultimately, the product oriented paradigm had produced a failed pedagogy, leading to a crisis in the English-speaking world of academic writing in the 1960's and 1970's. The failure was based on, as Hairston (1982) claimed, three inaccurate assumptions about writing: (1) Competent writers knew what they were going to say before they began to write; thus their most important task when they were preparing to write was finding a form into which to organize their content, (2) the composing process was linear and proceeded systematically from prewriting to writing to rewriting, and (3) teaching editing was teaching writing. Therefore, she surmised,

Teachers who concentrate their efforts on teaching style, organization, and correctness are not likely to recognize that their students need work in invention. And if they stress that proofreading and editing are the chief skills one uses to revise a paper, they won't realize that their students have no concept of what it means to make substantial revisions in a paper. The traditional paradigm hides these problems. (p.80)

During the early 1970s, when scholars like Emig (1971) and Elbow (1973) were conducting groundbreaking research into the process of composition and exposition, they revealed contradictions of the traditional product paradigm, as Hairston (1982) identified below: 
Most writers have only a partial notion of what they want to say when they begin to write, and their ideas develop in the process of writing ... and that the writing process is not linear [but rather] ... messy, recursive, convoluted, and uneven [and finally] ... writers write, plan, revise, anticipate, and review throughout the writing process. (p.85)

Their and other similar research launched a new paradigm in academic writing studies which became known as the writing process movement. In this paradigm, writing was no longer conceived of as a textual artefact but rather, as Hairston had observed, a multi-step cognitive process that included recursive brainstorming, pre-writing, writing, and revising. The writing process was viewed as pertinent to creating meaning because, in Elbow's (1973) words, "meaning is not what you start out with but what you end up with" (p.15). During that time, students were encouraged to free write rather than research, focus on content rather than form, and present personal ideas as strategic means to writing academically. This paradigm also lead to the creation of the Writing Across the Curriculum (WAC) program, which, as Strachan (2008) explained, "emphasized writing as a tool for learning in potentially every context ... [where, according to Hilgers, Jussey \& Stitt-Bergh, it] typically emphasized writing processes (prewriting, drafting, revising, editing) and products (journals, learning logs) that could be adapted to any course" (p.239).

Scholars in academic writing studies, such as Moffett (1968), Britton (1975), Kinneavy (1971), Shaughnessy (1977), and Emig (1971), added to the growing body of research when they argued the following, as presented by Young and Fulwiler (1986), "student writing will not improve substantially until students see writing at the center of 
their academic curriculum; that is, until they learn to value writing, and to practice it in the daily business of learning in all disciplines" (p.1). This awareness shifted the attention of writing scholars from general processes of writing to writing within a specific context and, as a corresponding response, a shift from WAC to Writing in the Disciplines (WID) programs was implemented at several universities. At the same time, as a response to the growing recognition that writing may be challenging for students, writing centres began to appear across university campuses.

The complexity of academic writing continued to receive attention throughout the 1980's, and ongoing research by such scholars as Nystrand (1984), Bizzell (1986), and Faigley (1986) led to another paradigmatic shift, with the new paradigm recognizing writing as a social activity in addition to being a cognitive process. This new understanding of writing appeared to provide a fuller picture of the university student as a writer--one who is influenced by "the social-rhetorical situations in which writing gets done, the conditions that enable writers to do what they do, and from the motives writers have for doing what they do" (Reither, 1985, p.621).

As a result of the recognition of writing as being part of a social context, the notion of genre was also reconceived. Traditionally, genres were seen as text types that were "defined by regularities in form and content" (Freedman \& Medway, 1994, p.1), while the reconeeived notion of genre focused on the "typical ways of engaging rhetorically with recurring situations" (p.2). That is, regularities in form and content were now being viewed as echoes of underlying rhetorical regularity. For example, if a professor wanted to send a student with very low grades to see an academic counsellor, she many choose a form to initiate this request that required the student's signature in 
order to indicate that the student was well aware of the professor's request. Because the professor wanted the student to know of her concerns and wanted the counsellor to know that the student was informed of these concerns, this social need lead to the form having space for the student's signature. This most recent understanding of both writing and genres as social activities has lead to the development of several directions for academic writing pedagogy discussed later in this section.

\section{Research into Academic Writing}

On the basis of their research, scholars (e.g., Bruffee, 1984; Dias et al., 1999; Giltrow, 2002; Hunt, 1993; Paré, 1994; Reither \& Vipond, 1989) have presented various views about academic writing that can serve to provide directions for academic writing pedagogy. Awareness of these views may help teachers and professors to understand the difficulties that students face in their writing and may assist them in developing writingfocused syllabi. Some of these views that are most relevant to understanding students' perceptions of writing at university are presented in this sub-section.

Insights for academic writing pedagogy

To begin with, the notion of writing as a distinct skill, which was left over from the product paradigm in the history of academic writing pedagogy, as discussed in the previous section, seems to be well established in academic and professional environments. For this reason, many universities still have mandatory first-year composition or writing courses. However, Reither and Vipond (1989) contended that "there is no such thing as knowing how to write, there is only knowing how to write in certain genres for certain audiences on certain subjects in certain situations" (p.866). Dias et al.(1999) echoed this and added the view of the influence of subjectivity of 
writing: "Writing does not occur in a social vacuum ... the context in which any given writing occurs is integrally part of that act of writing ... where the writer is, when he/she is writing, and who he/she is writing to or for, may precipitate inarticulateness or give rise to apparently serendipitous or inspired formulations" (p.17). It seems that these scholars were rejecting the interpretation of writing as neatly fitting many different situations, but rather believed that each situation is unique and requires a different style of writing. The subjectiveness of these distinct situations is what makes each piece of writing unique. These scholars were describing writing that is meaningful, writing that is relevant. Reither and Vipond (1989) did just that, when explaining the importance of providing students with topics for research assignments, in which the students were interested and which students perceived to be relevant to the content of the course they were studying: “[They will] learn to read ... [research] articles [for their projects] with greater purpose and skill because they're reading them for their own uses, to satisfy their own needs" (p.866). Bruffee (1984) echoed the necessity for perceived relevance in learning and recommended that students should be provided with the opportunity to read about and discuss particular subject matter before having to write about it, as this may develop their interest in and understanding of the subject and therefore, lead to greater meaning for them.

Bruffee (1984), following the lead of earlier theory (Moffett, 1968), suggested that one way of providing students with the opportunity to discuss relevant subject matter in the classroom is through peer collaboration; that is, providing a classroom context in which students "talk about the subject and about the assignment ... they talk through the writer's understanding of the subject ... and most of all they converse about and as a part 
of writing" (p. 645). I recognize that implementing peer collaboration projects in the classroom requires an additional effort from teachers for set-up and monitoring, but it may provide them with both extrinsic rewards, where the students may produce higher quality work because the environment is more conducive to meaningful learning, and intrinsic rewards, where due to the enhanced learning situation, teachers may experience a more effective working environment.

Paré (1994) supported the idea of collaborative learning, as he viewed it as an excellent means for students to develop writing skills. He felt it was "unfortunate that students put so much effort into research and writing and end up sharing it with no one but the teacher ... when students work together, they teach each other" (p.9). Through a collaborative experience, students may sense the relevance of their contribution and therefore, may perceive greater meaning in the work they are engaging in. Furthermore, Paré identified collaborative learning as a social process that provides an opportunity for students to participate in a greater conversation by sharing their perspective on subject matter. Unfortunately, it is more likely that an average student perceives herself, as Paré suggested, as a "commentator on, rather than a contributor to, disciplinary conversations" (p.8) because most often, she is not aware of her potential to contribute. This is likely a result of many students' view that a major purpose of writing at university is to report on a topic according to what scholars have said. This view has developed because most students, particularly in first-year, do not perceive that their opinions are relevant, (perhaps because they are told by teachers these are not), which leaves them with the option of basing their writing on others' thoughts. 
Giltrow (2002) suggested that it might be easier for students to perceive their contributive role in writing as a meaningful social act if they gained an awareness of the concept of style in writing because "style constitutes a position in the world and shared methods for thinking about it" (p.10), or, as Bakhtin (1986) indicated, "Where there is style, there is genre" (p.66). Giltrow was referring to a shared knowledge of genres that translates into a sense of belonging from a mutual understanding of the current conventions for a particular genre. Thus, if students can learn to identify a genre and are able use it, they may feel a sense of belonging to the discourse community (Swales, 1988) that this genre is a part of. This may then contribute to the meaningfulness with which they write, as they will have gained the knowledge that they are actively participating in something that is recognized and valuable.

In order to begin to identify genres and gain a sense of the discourse communities to which the genres belong for the purpose of writing more meaningfully, students must, according to Hunt (1993), be provided with relevant readings that their writing can be based on. He targeted textbooks as not being "created because someone had a point she wanted to make to a real audience" (p.5) but rather, because there are curriculum formulas to fill and committees to please. Hunt claimed that even "real" texts brought to the classroom from the outside world are empty of meaning as they are simply "a pretext

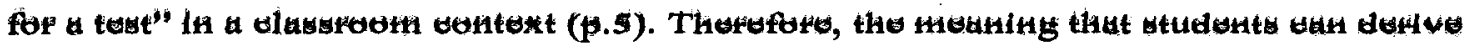
from reading and writing for a grade alone is limited. There must be something greater beyond this target; something that matters; something relevant. Hunt claimed if the above is not provided to the students and they do not "read for meaning... [they can't be expected to] write to convey it" (p.7). 
As discussed above, these insights about academic writing may help teachers and professors to understand the perceptions that students have about academic writing and may provide directions for academic writing pedagogy. Ultimately these directions may lead to the development of improved writing competence for students. It is apparent from these insights about academic writing pedagogy that in order for students to participate in relevant learning experiences, students need to perceive meaningfulness in their readings, their assignments, and their classroom experiences. This may allow them to engage with writing to help them to think, which will produce writing that reflects this thinking.

Research on students' perceptions of their writing needs

Among a relatively limited number of publications on students' perceptions of academic writing, the four reviewed below address issues that are directly relevant to this study. This review focuses on the discussion of the students' perceptions of a) the value of feedback on their assignments, b) language used for explaining assignments and delivering written feedback, $c$ ) the expectations for writing assignments, and d) the role of writing at university.

Weaver (2006) observed that the majority of student participants perceived constructive criticism on assignments as necessary for improvement in their writing and as a means to filling in knowledge gaps. Unfortunately, due to the actual feedback that students in Weaver's study had received on various assignments over a year being too vague, lacking guidance, overly negative, and too late to be of use, the students did not perceive this feedback to be helpful in improving their performance on their assignments. In addition to the positive perception of constructive feedback, a large majority of the 
students in Weaver's research perceived that positive comments had increased their confidence, and a minority of students perceived that negative feedback caused feelings of despair, anger, and demoralization. Regardless of the type of feedback received, most students reported that, at a minimum, feedback lead them to reflect on what they had learned and perhaps this in itself might lead to requesting guidance from teachers and ultimately to writing improvement. Regarding the value of feedback in students' eyes, Krause (2001) discovered that students perceived ongoing feedback from their professors to be helpful for improving their written assignments. The students appreciated when their professors were available for discussion about the assignment both before beginning to write and during the writing process. In Lea and Street's (1998) study, the students valued feedback on their written assignments but highlighted that they often did not understand that feedback. This latter point leads us to examine the language that professors are using for their assignments and in their feedback on the students' papers. Most noteworthy, more than half of the students in Weaver's (2006) study also claimed that they were often unsure of the meaning of some of the language used in the feedback on their papers. This leads us to suspect that the students' perceptions of the feedback as being vague, lacking guidande, and overly negative may be based on a misinterpretation of the language used in feedback, rather than being an accurate account of the actual feedback. Weaver speculated that students' struggles with the language of teachers' feedback were related to the professors' 'assumptions about students' ability to interpret their comments accurately" (p.390).

This possibility of miscommunication between students and professors was investigated in Lea and Street's (1998) study, where they revealed that the tacit 
disciplinary knowledge that faculty possessed often interfered in communicating both clear assignment expectations and understandable feedback for students. Professors thought they were providing clear assignment expectations and feedback on the assignments, which were "not readily understood by students unversed in that particular orientation of the discipline" (p.162). Furthermore, although students were aware of diverse disciplinary writing expectations, they admitted to being confused on how to write about specific course-based knowledge within a particular discipline. This illustrates how it is difficult for students, especially first-year students, to write their assignments when many do not understand the language being used to describe these assignments.

In addition to the actual language used for their assignments, there were several other issues that students perceived as contributing to the clarity of their assignment expectations. Krause (2001) reported that, first, students perceived the importance of obtaining samples of past assignments in order to help them get started on their assignments because they believed that samples would provide them with an image of what they needed to produce. Second, students perceived that peer collaboration in discussing the assignments would make up for hesitancies in communicating with their professors, whom they avoided for fear of appearing stupid. Third, the students perceived that a comprehensive library orientation would be helpful in familiarizing them with content that might clarify their assignments' expectations, such as contrasting information on a topic that they are advised could be used in a comparative analysis assignment. Another factor that students perceived as lending to the clarity of their assignment expectations, as reported by Sommers and Saltz (2004), was seeing their 
assignments to have a greater meaning than simply completing a requirement for a course. They found the assignment expectations easier to understand when they perceived that they could write about something that mattered to them.

In examining the meaningfulness of writing, Sommers and Saltz (2004) revealed that the majority of students recognized writing "as an opportunity to think and ... show [themselves] as ... credible thinker[s] (p.128). They seemed to highly value the role of writing at university and recognized writing assignments as an opportunity to better understand the content of a course. In contrast, the students referred to the content of the courses that did not include writing assignments as information that is to be "regurgitate[d] on exams but never digest[ed] for themselves" (p.130). In contradiction to Sommers and Saltz' observations, the students in Lea and Street's (1998) study did not perceive the role of writing as an opportunity to think and display their abilities as writers. Instead, they often did not consider their own ideas to be valid contributions and therefore, "as novice students [they could not imagine writing] anything that they had not read in an authoritative source" (p. 166). It is hard to confirm the exact reasons why there was this difference between the students' perceptions of writing, but I can offer speculation about these reasons based on the professors' perceptions of the most important aspects of writing, as reported in these two studies, and the time of the year when students provided their responses. First, regarding perceptions of the most important aspects of writing, in Sommers and Saltz's study there were not any professors interviewed, but one of the researchers observed an in-class lecture from a course on moral reasoning. She reported that the professor gave the students the opportunity to critically reflect on their own opinions regarding existing societal debates, using the 
theories in the course to inform their opinions. The researcher surmised that it was the opportunity to join a debate that lead the students to perceive meaning in their writing for that course. In contrast, the professors interviewed in Lea and Street's study defined the most important aspects of writing in terms of form such as "syntax, punctuation and layout...structure, argument, and clarity" (p.161). Regarding these last three items, Lea and Street reported that each professor's particular disciplinary background influenced how these items were taught and these differences lead to difficulties for students who were unfamiliar with disciplinary knowledge. Perhaps the focus on form influenced the students in that study to perceive themselves as nothing more than receptacles of contradictory information without any permission to express their ideas.

Second, the time of year that the students' responses were collected could have influenced the students' perceptions of the role of writing at university. That is, with increased exposure to disciplinary knowledge and familiarity with the disciplinary discourse, it is possible for the students' perception of the meaningfulness in their writing to change. In Sommers and Saltz's study, it was at the end of the first-year, whereas in Lea and Street's study, it is not specified when the students provided their responses. Whether these two factors have an influence on students' perceptions of the role of writing at university was not confirmed by either of these studies but certainly is worthy of future exploration. In the design of the present study, 1 puld particular attention to the time in students' academic studies when I wanted to interview them. It lead me to choose second-year students as main informants in the study as I expected their perceptions to be formed over the first year of their studies, as discussed in detail in the Methodology section. 
The research reviewed in the above section has demonstrated that students undergo transitions while gaining new knowledge, or, as Lea and Street (1998) observed, "learning in higher education involves adapting to new ways of knowing: new ways of understanding, interpreting and organizing knowledge" (p. 157), and therefore, new ways of writing. In order to best help students who have limited understanding of the expectations and demands of university assignments, Sommers and Saltz (2004) suggested that professors view the "imperfections" in students" work "not as a flaw in ... writing but a symptom of a novice working on an expert's assignment" (p.135). In this way, the professors may be more likely to view the students' work as being in the midst of a process that will be built upon and strengthened throughout their time at university. The following chapter provides the methodology of the study. 


\section{Methodology}

This study is set in the qualitative research paradigm as defined by Strauss and Corbin (1990) as research about "persons' lives, stories, behavior . . . organizational functioning, social movements or interactional relationships" (p.17). The methods used in this study were influenced by the constructs of grounded theory where the purpose is to “reveal participants' views, feelings, intentions, and actions as well as the contexts and structures of their lives" (Charmaz, 2006, p.26) in order to form ideas from the data. That is, my goal was to understand the writing needs of first-year university students as seen from the perspectives of both the students and the instructors and, in doing so, I needed to consider the social, individual, and educational factors that contributed to the participants' perceptions.

I chose interviews as my main data-gathering instrument as, according to Creswell (1997), these "play a central role in the data collection in a grounded theory study" (p.122). This study has emergent design, integral to a grounded theory study (Charmaz, 2006), where "one begins with an area of study and what is relevant to that area is allowed to emerge" (Strauss \& Corbin, 1990, p.23), which allowed me to design a set of questions that served as a guide for conducting semi-structured interviews with the participants (see Appendix A, p. 113 and B, p. 115). During the interviews, the interview questions followed the participants' train of thought and at times, wandered from the prescripted questions I had originally prepared.

\section{Participants}

All participants in this qualitative study were situated at a medium sized Canadian University. They included five second-year students, a focus group of nine first-year 
students, and five professors. My sampling of participants was strategic, as it is suggested by Geisler (2004) to be a more defensible means (rather than merely convenient sampling) with which to "guide [my] choice of cases within a site" (p.18). I first used criterion-based sampling that "specif[ied] a certain relevant criteria" (Geisler, p.18) in choosing the study participants. Thus, the student participants were drawn from first and second-year, by means of volunteering, which enabled me to collect data on the perceptions from first-year students of their current experiences and comparative reflections from second-year students on their experiences with academic writing in the first (retrospectively) and second year. The professors, also participants by means of volunteering, are instructors of both first-year seminars and regular first-year courses, which are described below. Professors' experiences in these two settings provided me with an opportunity to gather data on their perceptions of students' writing needs in each of these classroom environments.

After choosing the participant sample based on these criteria, I then used a stratified sampling strategy to "take advantage of knowing something about the existing variations in a site" (Geisler, 2004, p.18) and chose both student and instructor participants from a variety of disciplines. This choice allowed me to compare the perceptions of professors and students on a disciplinary basia. Furthor stratifying amongst the second-year students based on varying first-year experiences allowed for examination of a variety of pedagogical environments that could affect first-year students' writing ability. These experiences included enrollment in one of the following:

(1) First Year Experience (FYE), which is an innovative attempt to facilitate the transition for first-year students to university by providing smaller classes (maximum 100 
students) that are enmeshed in a cluster of four pre-determined courses (the fifth course is of the student's choice).

(2) First-year seminar, either within or outside of the FYE, which provides an even smaller environment of approximately 25 students where the philosophy is to provide enhanced opportunities for the students to write in a variety of forms using multiple drafts, receiving comprehensive feedback on each draft, and where critical reading/writing are inherent in the assignments.

(3) Mandatory writing course, which is established as one semester of an English literature course.

(4) Academic Support Program, which provides the opportunity for university study to students whose high school grades were below the acceptable standard.

(5) Regular first-year course, which does not have any particular focus on writing and in this study, may have up to 100 students enrolled.

The individual student and professor participants as well as programs of study are identified by fictitious names in this thesis for the purposes of maintaining confidentiality. The participants in the student focus group are not identified by any personal name as they were not identified during the discussion. The individual participants are described as follows:

\section{Student Participants}

Second-year students. "I mean even if I get a good mark I think that anytime you get a mark less than perfect there has to be a comment or else why didn't you get perfect?" (Alana, March 25, 2009). Alana is 19 years old and English is her first language. Her major is Human Rights and her minor is Mass Communications. Alana is 
more interested in Mass Communications than Human Rights and plans to switch her major accordingly for next year. She was an above average student in high school where she was on the honour roll for two years. Her grades were lower in math and in the sciences than in the arts or social science courses as she claimed "they [those subjects] just came easier to me." Both of her parents have university degrees and they encouraged her to go to university. Alana described herself as an active reader who enjoys reading popular fiction in her spare time. In addition to reading, Alana is a competitive dancer, works as a server in a restaurant, and is a volunteer with a local youth organization. Alana was selected for this study as she had participated in a mandated first-year writing course at the university she previously attended.

"I think it's [writing] one of the cornerstones of education in university" (Ryan, February 25, 2009). Ryan is 20 years old and English is his second language, which he began learning at the age of 7. His major is History and his minor is Applied Language Studies. He described himself as a motivated student who is interested in learning about the discipline of history. Ryan described his high school academic experience as "pretty good" and he did not perceive any major problems adapting from high school to university. Both of his parents have university degrees and they expected him to go to university. Ryan enjoys reading, particularly fiction, listening to music, boxing, working out at the gym, camping, cycling, reading the news, and surfing the Internet. Ryan was chosen for this study as he participated in a first-year seminar outside of the First-year Experience program.

"I expect the professors to give a very clear definition of what their expectations are so that I'm not going off in a direction that won't be beneficial towards the end 
product" (Danielle, February 26, 2009). Danielle is 39 years old and both English and French are her first languages. Her major is Political Science and her minor is Religion. She is a highly motivated student and anticipated that a background in Political Science would give her a better knowledge base from which to understand the historical component of present day political issues and the Religion courses would help her to understand the perspectives of other people's cultures. Danielle was an average achieving student in high school and did not find it very challenging. Her mother did not finish high school and her father completed one year of college. Her parents are impressed and supportive of Danielle's decision to return to school. Danielle enjoys reading, particularly books of a philosophical nature. When she's not a full time student during the academic year, Danielle is an officer in the Canadian Forces, specifically in the field of logistics for the army, where she engages in military training during the summer months. Danielle was selected for this study as she participated in a first-year seminar within the FYE program.

"She kinda directed us through it and showed ... like ... this is one of the perfect papers, we didn't really go over it in detail but she definitely gave us access" (Paul, February 27, 2009). Paul is 22 years old and English is his first language. He took two years off between high school and university and now feels highly motivated to be in school. His major is Philosophy, which he believes he is well suited for as he claims this discipline allows him the freedom to argue his opinions rather than regurgitating facts. Paul enjoys school and is intending to do graduate work in this discipline. Paul was not a high achieving student in high school due to lack of motivation and is grateful that his teachers encouraged him to go to university. His parents were also encouraging, as his 
father, who has a university degree and his mother, who is in the midst of attaining one, both value higher education. Paul enjoys reading for interest but is consumed with academic reading during the school year. He also plays guitar and video games, enjoys on-line chatting and hanging out with friends. Paul was selected for this study as he was enrolled in the FYE program in first-year but did not take a first-year seminar.

“First-year was harder, obviously, and I didn't have that much to go on .. . because in high school you don't do anything, you really don 't"' (Sarah, March 14, 2009). Sarah is 19 years old and her first language is English although she was living in an Arabic speaking environment for the first two years of her life. Her major is Sociology, which she does not seem to have much interest in. She feels there is too much of a focus on writing assignments, which she finds cumbersome, and research methods, which she finds boring. She intends to stay with Sociology as she does not know what else to do. Sarah was not motivated in high school and her performance reflected that. Her parents, who both have university degrees, were very supportive of Sarah going to university. Sarah enjoys reading, drawing, painting, playing guitar, editing online music videos, and hanging out with friends. She was selected for this study as she participated in the Academic Support Program in her first-year at university.

First-year students. In addition to the identified second-year students, there was a focus group of nine FYE students in a first-year seminar in English who participated in this study through an open discussion within the context of their classroom. Initially, I was to observe this class during regular classroom instruction, but their professor had suggested that I conduct an open discussion with the students about their writing needs. She had offered this opportunity as the students had completed their writing assignments 
for the year and, therefore, she did not anticipate much relevant discussion in her class regarding writing instruction.

\section{Professor Participants}

The professors, Johnson, Andrews, Sinclair, Simmons, and Brown range in teaching experience from five to twenty-five years in the disciplines of English, Philosophy, Language Studies, Psychology, and History. They all currently teach firstyear students both within first-year seminars and outside. In addition, four of the five participants have also taught these seminars within the FYE program.

\section{Data}

The university ethics committee approved this study (see Appendix C, p.116) and I prepared and had completed consent forms for the participants. The data gathering instruments used in this study included: (1) interviews, (2) class discussion, and (3) samples of students' academic writing. Pre-designed questions guided the interviews and class discussion, yet the semi-structure nature of the interviews allowed for divergences as necessary (see interview questions in Appendices A and B).

The writing samples that were used included any two graded papers from each second-year student: one that they had written in first year and one in second year, which facilitated our diaguagion on their writing stylea, ehanges to their writing that may have occurred between first and second year, and written instructor feedback that may have hindered or helped their writing. An additional aim for the collection of student texts was for the purposes of data triangulation, which Tashakkori and Teddlie (1998) refer to as a technique of data collection to study the same phenomenon within the same study (p.18). Furthermore, Lincoln and Guba (1985) insist on triangulation as a requirement to shed 
some validity on study revelations: "As the study unfolds and particular pieces of information come to light, steps should be taken to validate each against at least one other source (for example, a second interview) and/or a second method (for example, an observation in addition to an interview). No single item of information ... should ever be given serious consideration unless it can be triangulated" (p. 283). Thus, in this study, I reviewed students' texts as a means to discover if what the students and professors were identifying as writing problems were reflected in the texts they produced.

\section{Procedures}

The interviews of all of the study participants occurred over a two-month period. I met with each of the individual student participants, on two occasions, each approximately 30 minutes in length. All of the students appeared to be at ease during the interviews and seemingly excited for the opportunity to express their thoughts on this topic. The interviews took place in a private office on the university campus and were audio recorded and later transcribed into MS Word documents, which served as the basis for analytical coding. I also made observational notes that were added to the data pool.

The interview questions for the individual student participants were comprised of three parts and were divided over two interviews (See Appendices A and B). The initial interview concentrated on the first and second parts that covered questions on personal history such as language and family background, academic motivation and performance, and extracurricular interests, as well as perceptions of students' academic writing needs and the support they have received to meet these needs. The second interview centred on the third part of the questions, which focused on the differences in the students' writing as per their two provided assignments and corresponding feedback. 
Prior to the second interview, I read the student's texts; highlighted the editorial marks, corrections and comments that were made by professors or TAs on the papers; and noted differences in style, structure, and form between the text written in the firstyear and the text written in the second-year. The second interview had two purposes and was conducted using a discourse based interview approach (Odell, Goswami \& Herrington, 1983) "to help uncover writers' tacit knowledge of, and motivation for, texts" (Prior, 2004, p.196). The first purpose was to see how the students interpreted and were affected by the comments made on their papers and the second was to gain insight into how the students knew how to write within a particular genre (e.g., Sarah had to write a comparative analysis of theoretical approaches to understanding a sociological phenomenon).

I met with the focus group of nine first-year seminar students on one occasion for approximately 30 minutes. During this time, the professor had purposely exited the classroom to encourage her students to express their thoughts freely. I had arranged the seats in a semi-circle, placing myself at the top-middle position in an attempt to create a more intimate and comfortable environment for the students. The discussion was guided by the following four questions I had prepared: (1) What is the role of writing in the university? (2) What are your attitudes about school writing? (3) What are your greatest obstacles to becoming better writers? (4) What are some sources of help you have received or could receive to improve your writing? In keeping with the emergent design of the study, further questions and topics for consideration arose throughout the discussion. 
The discussion was audio recorded after I had asked the students for their permission to do so. During the discussion, I initiated the questions and asked for the students' opinions. Five out of the nine students verbally participated in the discussion. I avoided asking specific students their opinions not only because I didn't know their names but also because I intended this discussion to be a comfortable means for the students to express themselves and was not interested in putting anyone on the spot. Before leaving, I invited the students to contact me by email if anyone had some afterthoughts that they'd like to share. For the record, I have not received any further commentary.

I met with each of the five professors in their offices on the university campus. We met on one occasion for approximately 40 minutes where the interviews were audio recorded. The interviews focused on the professors' opinions of the writing needs of first-year students and the supports that should be in place on campus to address these needs. All of the participants were seemingly open, comfortable and eager to partake in the interviews.

I transcribed all the interviews. Following the transcription of each interview for both the individual students and the professors, I forwarded each participant a copy of his or her transcribed interview to obtain member checks, which is, according to Lincoln and Guba, "to be the most critical technique for establishing credibility" (as cited in Cresswell, 1998, p.203). The partielpants reported an overall satisfaetion with the text and only requested minor changes to ensure their personal confidentiality. I made all of the requested changes. 


\section{Analysis}

As students' perceptions of their writing needs are the main focus of this study, I began the analysis with the data that emanated from these participants and then, afterwards, compared it to the data collected from the professors. Geisler (2004) informs us that, "although many strains of qualitative analysis exist, most involve coding segments of verbal data as a way of locating phenomenon of interest" (p.xix). Therefore, to analyze my data, I used the coding premise of Grounded Theory which Strauss and Corbin (1990) define as a theory that is "inductively derived from the study of the phenomenon it represents" (p. 23) with a purpose "to build theory that is faithful to and illuminates the area under study" (p.24). Furthermore, Charmaz (2006) asserted that Grounded Theory coding is an essential tool for data analysis, referring to it as "the pivotal link between collecting data and developing an emergent theory to explain these data" (p.46).

Strauss and Corbin (1990) inform us that, "coding represents the operations by which data are broken down, conceptualized, and put back together in new ways" (p.57). For data analysis in this study, I used their method of open coding, which they defined as "the part of analysis that pertains specifically to the naming and categorizing of phenomena through close examination of data" (p.62). There are three stages to Straus and Corbin's open coding proesse that inelude a) labeline phenomena with descrintive codes, b) categorizing descriptive codes into concepts, and c) combining concepts into overarching themes. The three stages of coding are presented in Figures 1-3. At the first stage of the coding process, I followed Strauss and Corbin's recommendation of making concepts my basic unit of analysis, which entailed labeling phenomena as follows: 
Taking apart an observation, a sentence, a paragraph and giving each discrete incident, idea or event, a name, something that stands for or represents a phenomenon. Just how do we do this? We ask questions about each one, like: What is this? What does it represent? We compare incident with incident as we go along so that similar phenomena can be given the same name. (p. 63)

An example of an excerpt from an interview with a student in Figure 1 is an illustration of this type of coding.

\begin{tabular}{|l|}
\hline QUESTION \\
\hline $\begin{array}{l}\text { Do you think that there is } \\
\text { something that a teacher can } \\
\text { do in the class that would } \\
\text { help students with their } \\
\text { writing? }\end{array}$ \\
\hline
\end{tabular}

\begin{tabular}{|c|}
\hline RESPONSE \\
\hline $\begin{array}{l}\text { The teacher could... well } \\
\text { first of all just give a } \\
\text { lecture on what they expect } \\
\text { from the writing. }\end{array}$ \\
\hline $\begin{array}{l}\text { Like simple...not darting } \\
\text { around it...just being } \\
\text { straightforward... }\end{array}$ \\
\hline $\begin{array}{l}\text { They do give syllabi and } \\
\text {...outlines, but sometimes } \\
\text { it's confusing... }\end{array}$ \\
\hline $\begin{array}{l}\text { Because they don't provide } \\
\text { examples... }\end{array}$ \\
\hline $\begin{array}{l}\text { And I find examples are } \\
\text { always the best way }\end{array}$ \\
\hline
\end{tabular}

\begin{tabular}{|l|}
\hline CODE \\
\hline $\begin{array}{l}\text { Asking for and suggesting } \\
\text { clear expectations for } \\
\text { assignments }\end{array}$ \\
$\begin{array}{l}\text { Instructing how } \\
\text { expectations can be } \\
\text { communicated easily }\end{array}$ \\
$\begin{array}{l}\text { Recognizing the value in } \\
\text { these texts but not quite } \\
\text { enough for clarification }\end{array}$ \\
\hline $\begin{array}{l}\text { Indicating examples are } \\
\text { superior for learning }\end{array}$ \\
\hline $\begin{array}{l}\text { Relying on experience as a } \\
\text { guide for best practice }\end{array}$ \\
\hline
\end{tabular}

Figure 1. Example of labeling phenomena with descriptive codes

After having labeled the phenomena with descriptive codes, I engaged in Strauss and Corbin's (1990) second suggested stage in the open coding process--discovering categories. Strauss and Corbin described the categorization stage in the following way: 
"Once we have identified particular phenomena in the data, we can begin to group our concepts around them. This is done to reduce the number of units with which we have to work. The process of grouping concepts that seem to pertain to the same phenomena is called categorizing" (p. 65). These scholars then suggested that the categories be given conceptual names that are more abstract than the concepts that are grouped under them. For example, in Figure 1, I grouped the identified concepts into a category called clear expectations. Figure 2 is a presentation of the conceptual categories that were formed in the second stage of the coding process. The conceptual categories are listed based on the order in which they were recognized following the first stage of coding.

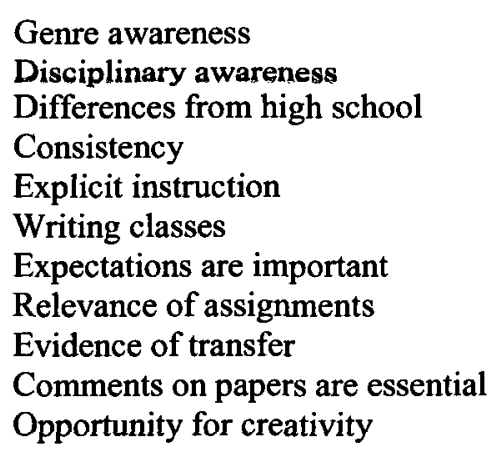

Figure 2. Conceptual categories

After having categorized the concepts, I began a third stage of coding, which is based on Strauss \& Corbin's (1990) premise of axial coding as "a set of procedures whereby data are put back together in new ways after open coding, by making connections between categories" (p.96). Strauss and Corbin's focus is on specifying a sub-category "in terms of the conditions that give rise to it; the context in which it is embedded; the action/interactional strategies by which it is handled ... and the consequences of those strategies" (p.97), whereas I have chosen to simply reassemble the 
identified categories to form overarching themes. I based this strategy on Charmaz's (2006) suggestion that "those who prefer simple, flexible guidelines--and can tolerate ambiguity--do not need to do axial coding. They can follow the leads that they define in their empirical materials" (p.61). Figure 3 is an illustration of the outcome of the third stage of coding; that is, it presents the overarching themes that resulted from combining the categorized concepts in Figure 2.

\begin{tabular}{|l|}
\hline CATEGORIZED CONCEPTS \\
\hline $\begin{array}{l}\text { Differences from high school } \\
\text { Relevant assignments }\end{array}$ \\
\hline $\begin{array}{l}\text { Comments on papers are essential } \\
\text { Evidence of transfer }\end{array}$ \\
\hline $\begin{array}{l}\text { Explicit instruction } \\
\text { Opportunity for creativity }\end{array}$ \\
\hline $\begin{array}{l}\text { Genre awareness } \\
\text { Disciplinary awareness } \\
\text { Writing classes }\end{array}$ \\
\hline
\end{tabular}

\begin{tabular}{|l|}
\hline THEME \\
\hline Consistency in Instruction \\
\hline Constructive Feedback \\
\hline Clear Expectations \\
\hline Writing Support \\
\hline
\end{tabular}

Figure 3. Overarching Themes

In addition to analyzing the interview data, I examined two samples of writing from each of the second-year students for further triangulation possibilities. That is, 1 wanted to investigate if the students' writing samples matched what they and the professors identified as their problems in writing. I used the existing Diagnostic English Language Needs Assessment (DELNA) (Knoch, 2009) rating scale as a guide for my analysis. DELNA, according to Knoch, includes nine traits, also called "subskills," 
(organization, cohesion, style, data description, interpretation, development of ideas, sentence structure, grammatical accuracy, vocabulary, and spelling), each consisting of six band levels ranging from four to nine (p.279). (See Appendix D, p.117 for a copy of the DELNA rating scale, Appendix E, p.118 for copyright permission to use the DELNA scale and Appendix F, p.119 for a comparison of the participant students' papers using the DELNA scale). Although I recognize, as White (1985) has proclaimed, that "there is no evidence that writing quality is the result of the accumulation of a series of subskills" (p.123), an analytic rating scale can identify areas of confusion and may provide, as White (1985) has further asserted, "a reasonable response to the pedagogical need to do what one can for students with varying needs" (p.122) by helping them to set and attain reasonable goals for improvement in their writing. Therefore, I chose the DELNA rating scale as an acceptable tool for comparison of the students' papers but acknowledge that its reliability and validity may be questionable in reflecting the students' true abilities. 


\section{Findings}

In interviewing first and second-year students about their perceptions of their first-year writing needs, I became privy to their attitudes towards academic writing: what they liked, what frustrated them, what they wanted, and what they presumed to know. In triangulating the findings, I examined the students' marked assignments and interviewed professors regarding their perceptions of first-year students' writing needs to determine if students' and professors' perceptions, and therefore expectations, were similar and if there were gaps between the students' perceptions and the reality of their writing abilities as presented by their papers. The findings of this study provide us with a glimpse into the perceptions of students' academic writing needs.

Although the five individual student participants, who had been selected from a volunteer pool with the defining characteristic of being in their second year at university, it may be worth mentioning that they share possibly significant attributes. First, all the students are active readers, second, their parents are supportive of their post secondary educational endeavours, third, they are engaged in several extra-curricular activities, fourth, they are B+ - A students, and fifth, they are fairly motivated students. It is not within the purpose of this study to investigate the potential relationships amongst personal characteristics of students and perceptions about their academic writing needs. but it may be a worthy future undertaking in order to reveal contributing factors towards these perceptions. However, it is the direct purpose of this study to examine first-year students' writing needs from the perspective of the students and the professors. The findings of this study are presented below, beginning with the students' perceptions, 
followed by the professors' perceptions, and ending with the findings from the analysis of students' writing samples.

\section{Students' Perceptions}

Based on the data received from the interviews with all the student participants, I have thematically categorized their perceptions of their writing needs in the first-year into the following four dominant themes: (1) Clear expectations for assignments, (2) Constructive and expansive feedback on assignments, (3) Meaningful assignments, and (4) Writing support.

\section{Clear Expectations}

The students iterated that they wanted their assignments presented with distinct assignment sheets that included clear expectations for type of assignment, citation style and samples, in order that they're not left on their own to figure out what to do. They concurred that they commonly engaged in frustrating rounds of trial and error regarding their assignments in first-year, as they were often uncertain of the assignment expectations and how to locate helpful sources for completing them. A first-year student from the focus group illustrated this:

How are we supposed to know that this is what our assignments are supposed to look like if they don't say it? Like, many articles are very different, which way am I supposed to write it. I mean if the Prof says this is a good example of how I expect you to write then that gives us guidelines, otherwise how do we know?

(March 16, 2009)

Alana, a second-year student offered what she considered simple suggestions for improvement to assignments: 
The teacher could ... well first of all just give a lecture on what they expect from the writing. Like simple ... not darting around it, just being straight forward ... and they do give syllabuses and they do give outlines but sometimes it's confusing ... sometimes ... they don't ... provide examples and I find examples are always the best way ... and then have assignments in class where you're actually practicing ... (March 25, 2009).

A first-year student from the focus group added to the premise of wanting to be told exactly what was expected for assignments: "I don't mean teaching us how to write, but telling us what they want" (March 16, 2009). Alana and her peers clarified that they were not asking for easy assignments but rather, wanted their assignments to be somewhat challenging as they viewed themselves as ultimately responsible for their own learning; or, as Paul stated, "Like I'm the key to my education, I guess" (February 27, 2009). But due to the high stakes that assignments represent in a student's life, they believe it only fair that these should be presented in an easily understood manner. This is highly relevant for professors to be aware of, as it is suggested by Vygotsky's idea of working within a student's Zone of Proximal Development and confirmed by self-efficacy theory, as presented by Linnenbrink and Pintrich, (2003): "If students are given tasks and activities that are challenging but not too difficult, their efficacy will increase as they experience success" (p.133).

It is interesting to note that despite the students pleading for unequivocal assignment expectations, they still wanted the opportunity to express their individual creativity. A first-year student expressed this desire when he stated the following: 
There isn't a lot of free thought. Like I really enjoy writing, like personally, but at school, there's so many rules that you can't express yourself without breaking the rules, you know what I mean? I signed up for Arts not Science ... and it's kinda like they turn writing into a science and it's not an art anymore. (March 16, 2009)

\section{Constructive and Expansive Feedback}

The students revealed that feedback on their papers is important to them and they believe that it can serve as a valuable tool in improving their writing if constructive and expansive. Second-year student Danielle confirmed this: "I got a couple of papers back and the professors made suggestions on them - you could have done it like this, do it like that, and then when I did the second paper, I went from a C to a B+ because I used the suggestions" (February 26, 2009). Sarah said:

I'd rather wait a week or two more to get my paper back so that the teachers... have more time to grade it, with useful comments or advice rather than get it back really quickly but there'd be nothing on it for me to learn from. (March 14, 2009) Unfortunately the students feel that many times, the feedback they receive is vague, limited, or non-existent. Second-year student Alana confirmed this: "Comments like... expand ... and anything that's really general ... that doesn't really help you because ... ok, expand more ... what do you mean ... what part do you want me to expand?" (March 14, 2009). Several of the students reported that the lack of constructive and expansive feedback causes a great deal of frustration for them, as they not only rely on learning from their mistakes but also feel discouraged if the teachers do not take the time to fully critique their work after putting considerable effort towards completion of an 
When I got the paper back, they said nothing about my writing or my perspective and just go right into grammar. I put seven hours into this and you [the professor] gave me one line of writing back: 'great idea, could have been better'. (March 16, 2009)

\section{Meaningful Assignments}

The students unanimously appreciated the importance of writing at university and in the workplace. They wanted to be able to write well and valued this as an asset in life. Second-year student Danielle expressed her knowledge of the significance of writing in the university:

As a student I want to demonstrate to my teacher that I have grasped what they have taught me, projected what I'm personally interested in and shown where I want to go from here ... I could do that ... with a well founded academic paper. (February 26, 2009)

Second-year student Paul reflected his knowledge of the importance of writing in the workplace:

To me it is very important to at least write coherently and write properly because . .. yeah, even at work ... some of the signs that are put up at work, there's like three misspelled words and I'm not sure if it's a typo and I think they just misspelled it and personally that makes me lose a lot of respect for them. (February 27, 2009)

Since the students attributed a reasonable amount of value to their writing, it was also important to them to perceive meaningfulness in the work they were doing at university. They felt this directly affected their motivation and thus their ability to succeed at their 
studies. Their commentary about meaningfulness was aimed in two distinct directions: 1) Consistency between what they learn and use at high school, university, and the workplace, and 2) Perceived meaning for and amongst their assignments and courses. Regarding consistency in learning between high school and further education, most of the students experienced learning the five-paragraph essay in high school as the dominant form for academic writing, and were distressed to learn that this was not the acceptable form at university. One of the first-year students seemed to view this transition as a harmful scheme: "Why are we being set up to have problems in university?" (March 16, 2009). Alana, a second-year student reported her concerns as follows:

I mean in high school we're told, pretty much ... the five-paragraph essay; intro, body, conclusion. That's how you write ... then you get into university and you're supposed to throw that all out of the window pretty much. I'm wondering if a lot of other students are saying like wow, the teaching is really different and what we are learning and how to write properly changes and so it sort of throws you off ... so it's just frustrating because it would be nice to have a consistent style that's just built upon. (March 26, 2009)

Alana and her peers did not understand the purpose for being taught something throughout high school, if it was going to be completely discarded at university. This reality seemed to instill a fear in the students that what they are then learning in university will be irrelevant to the workplace. Furthermore, several students spoke of a mistrust of the university environment as they felt they were being set up to have problems. In addition to the five-paragraph essay as an example of significant differences 
between high school and university writing, the students also spoke of a comparatively easy and lazy environment in high school versus university. Sarah reported: “[in] high school you don't do anything ... [and] it's really easy to pass ... university is different because it's all writing" (March 14, 2009). Summarizing the general feeling amongst the students of the disparity between high school and university is the comment from a firstyear student in the focus group: "Why is it that representatives from university don't discuss with high schools what's being taught?" (March 16, 2009).

In addition to the need for a sense of consistency between what is taught at high school and what is expected at university and then forward to the workplace, the students expressed a need to understand the connection between their assignments and ultimately between their courses. Alana was referring to a professor's expectation for globally applying a particular aspect of writing when she stated, "How can you use it in all your classes ... [when you don't understand why you are doing it]?" She later discouragingly added: "You never really learn ... the sort of . . importance of all that [assignments] ... I mean why it matters, it's just ... this is the way it is" (March 25, 2009). Danielle expressed her frustration over a perceived lack of meaning between her assignments and courses when she was reflecting on her first-year experience: "I got frustrated. I was like, why am I here?" (February 26, 2009).

\section{Writing Support}

In addition to clear expectations for assignments, constructive feedback on papers, and meaningful assignments, the students felt they needed additional support to improve their writing and offered suggestions regarding first-year seminars, the writing centre, library resources, and the FYE. Overwhelmingly, the second-year students agreed that a 
first-year seminar is the best resource for helping them to improve in their academic writing. In reflection, they recognized that smaller classes, where there was more dialogue, both amongst students and between students and their professor, increased writing opportunities, and typically more expansive feedback on their assignments provided them with a beneficial learning environment. The second-year students, more so than the first-year students, had an awareness of genre and disciplinary writing differences and therefore insisted that in order for first-year seminars to be successful in helping with writing, they had to be context based courses rather than general courses on writing.

The first-year students appreciated mostly the increased feedback they received on their assignments in their first-year seminar. Although these students did not have the same awareness of disciplinary differences that second-year students seemed to have, they supported context based writing opportunities as they anticipated that a noncontextual writing course that was not discipline specific "would not be beneficial because it would be redundant. We learnt this [variations on how to write an essay] in high school. So it would just be review. It would be boring and I wouldn't like it" (March 16, 2009).

Alana, who experienced a general writing course offered through the English department at her previous university, perceived some benefits to this course, but clearly recognized the disciplinary limitations: "In my first year, I took an English writing class and they gave us a lot of the ... more of the technical and the grammar and the structure of the essay ... so that was helpful because I learnt what was expected of me in English" (March 25, 2009). By stating that she learned what was expected of her in English, 
Alana leads us to believe that she did not perceive that she had been able to transfer any of the information from the writing course in English to her other courses in other disciplines. Furthermore, she expressed her awareness of genre and disciplinary differences when she said she learned what was expected of her in English, and also expressed this awareness as follows:

I just think there [are] different types of academic writing depending on what program you're in. I mean ok, if you're writing an English essay like ... this is what is expected of you and if you're writing an essay for philosophy or another class, this is what's expected of you ... writing essays compared to writing proposals or writing project outlines or ideas, it's going to differ. (March 25, 2009)

Another type of writing support at the university identified by student participants is the writing centre, which most of the students were not familiar with despite agreeing that it could be a helpful resource for improving their writing. The writing centre at this university is staffed by graduate students and carries the mandate to help students to become better writers through a collaborative and facilitative process that aids students in uncovering and structuring their ideas rather than offering proofreading services to correct students' papers. This mandate is based on the premise that Shaughnessy (1977) supported in her notable work, Errors and Expectations, "The absence of errors ... does not count much toward good writing" (p.11). At the university writing centre, the students are offered two 50-minute sessions per week where they can get help with their writing assignments. Although this sounds beneficial for students and all the study participants supported the notion of a writing centre on campus, only two of 
the second-year students accessed its services on one occasion each, which they perceived as relatively successful. A third student had received writing assistance on one occasion within the Academic Support Program and found it helpful, as she referred to the tutor as "really, really good ... He wouldn't give me the answers. He did it in a way that made me feel that I'm the one that did the hard work but he was the one that was pushing it out of me" (March 14, 2009). None of the first-year students from the study focus group had accessed the services at the writing centre and, in fact, only four of these students were even vaguely familiar with it.

The second-year students attributed their limited interest in attending the writing centre to a concern about time: "When I'm writing, I like to just get it done and I don't . . . normally like to spend a long time working on something" (Alana, March 25, 2009). Having said that, Alana was one of two students who did access the writing centre on one occasion; she reported that the tutor "helped me to structure and figure out a way to write that made sense." Despite her relatively successful experience, Alana did not return to the writing centre. Sarah suggested that if the students were going to make the time to go, it should guarantee them an 'A' on their paper or else it was not worth their time: "I had a friend last year who went. He had to go back like four times for the same paper and he only got a B+ on his paper. So results like that don't make you want to go" (March 14, 2009). Paul was concerned about the time it would take for a meeting at the writing centre and said that he preferred to consult with his friends who are working on similar assignments and who he is spending time with anyway: "She'1l [his friend] kinda lay out the information for me and say I just don't know where I'm going with this and then we kinda just work it out" (February 27, 2009). Little did Paul realize that he was 
reinforcing a concept of collaborative learning, as Bruffee (1984) explained: "Students' work tended to improve when they got help from peers" (p.638). Clark's (1985) study confirmed that students' most common reason for avoiding the writing center was a time factor and, "unless teachers require their students to visit the writing center, the students are unlikely to go or perhaps go only once" (p.33). Nevertheless, a writing centre is a common presence on many university campuses, which may indicate that enough students are accessing its services to justify its existence.

In addition to the writing centre as a physical place to access writing support, several of the students, both first and second-year, insisted that the library had the potential to offer valuable resources to help them with their writing assignments as they recognized the importance of the ability to successfully research a topic in order to produce a well written academic paper. Most of the first-year students recalled having a one off library orientation, which they found helpful yet by second term, they had often forgotten what they had learned and felt a refresher was necessary. Some of the secondyear students, such as Danielle, supported the idea of a refresher orientation:

l've been talking with teachers and other students and just trying to get ideas on how to better use the library when I'm looking things up, so I'm not wasting time going through stacks. I just want to know just where the different materials are 'cuz the materials in the library are so diverse and you can waste a lot of time. Be on the wrong floor. (March 25, 2009)

Another writing support program that was taken into consideration in this study, The First-year Experience (FYE), which was developed as an opportunity to comfortably initiate students into the university environment with small, clustered courses, was 
perceived as positive by all participants, whether student or instructor, who partook in this program. The participants did not report that this program provided better opportunities for directly improving writing or learning of any kind, but more so that the intimate environment of this program granted enhanced communicative opportunities between the professors and their students as well as amongst the students, an easy registration process, and greater relevance between their clustered courses. Regarding communicative opportunities in the FYE program, second-year student Danielle reported:

There is an opportunity for a student to voice their opinion and to have dialogue in a small group ... so for the first-year, it's a real advantage because you can have an open discussion going on about the topic and you can hear from all the different students with the professor there. (February 26, 2009)

Based on the students' perceptions of enhanced communication and the more overt connection between courses that are facilitated by the FYE program, it is reasonable to surmise that there may be an indirect effect on the students' availability to learning, and thus their writing competence, although this was not explored in this study and would be a worthy effort to investigate further.

\section{Professors' Perceptions}

The five professors who were interviewed for this study share common grounds in explaining why first-year students are having difficulty with academic writing. I have organized the interviow data into the followitis fout dominght themes (1) Orammar and mechanics, (2) The importance of writing, (3) Critical reading skills, and (4) Personal approach. 
Grammar and Writing Mechanics

All of the professors declared that many first-year students have weak skills in grammar and writing mechanics. According to them, punctuation, spelling, fluid sentence and paragraph structure, and thesis construction are not the areas many students come to university well versed in. Professor Andrews added: "One of the biggest problems for some of the students is they don't proofread and you can just see that in basic typographical errors" (February 10, 2009). Although these perceived weaknesses are admittedly frustrating to the professors since having to teach these rudimentary elements of writing reduces the opportunity for course content exploration, at the same time, they feel empathetic towards the students as they are convinced that the students have not had the opportunity to comprehensively learn these aspects of writing prior to university. Professor Simmons' sentiment towards this quandary, which was echoed by several of the other professors, is: "Teach the students you have, not the students you wish you had" (February 10, 2009).

The professors are divided on the value of teaching grammar and mechanics. Some of the professors asserted that these lower order concerns are secondary to the higher order concerns of clarity of argument, staying on topic, and flow of ideas and, conversely, some felt it was impossible to present any comprehensibility without the lower order concerns being addressed first. Consequently the students' exposure to academic writing guidance varied based on the attitude of the instructor.

Regardless of their particular philosophy of student writing improvement, the professors unanimously supported the concept of a writing centre on campus to aid students with their writing. In practice, however, the professors expressed several 
concerns about the services provided by the writing centre profiled in this study and therefore, they had not frequently recommended this service to their students. One common concern was the fact that the writing centre services were delivered by teaching assistants who the professors did not necessarily think were qualified for the role of a writing tutor. Professor Brown commented as follows: "I try to recommend things like the writing centre and ... without disrespecting graduate students ... it's just not appropriate having TAs doing that kind of work in my mind. TAs are not well trained" (February 12, 2009). Professor Johnson also emphasized her disapproval of teaching assistants as writing tutors when she explained that "there's going to be a necessary discrepancy between my idea of a coherent paragraph and somebody else's ... especially a teaching assistant who's still in the process of . . a student who's still in school" (February 12, 2009).

In addition to the possibility of under qualified writing tutors, Professor Johnson expressed another concern about the writing centre, which reflected a common difference in understanding the writing centre's purpose by professors and the writing centre's actual mandate, when she commented as follows:

I gomotimes wend atudents with really masive grammar, punctuation and spelling problems to the writing center and the help they get there is very various. I don't find them as helpful as I'd like and I don't send people there [often] ... [but] I would love it if students who really didn't know about grammar could go and find out and working one to one to understand how to use verb tenses for example. (February 12, 2009) 
That is, Professor Johnson would like the writing centre to explicitly help her students with grammar and writing mechanics, yet the mandate of the writing centre is to help students become better writers through a collaborative working relationship that prioritizes idea and structure development rather than a directive relationship that prioritizes grammar and mechanics correction. Professor Simmons echoed Professor Johnson's sentiment: "I don't think they (writing centre tutors) help students . . . they don't see it as their mandate to help students with basic things like grammar ... although the students need it" (February 10, 2009).

Since the professors seemed to perceive that the writing tutors are under qualified for their jobs and that the centre does not provide directive help with grammar and writing mechanics as the professors deemed necessary, their hesitancy to refer their students to the centre is understandable. It is reasonable to suspect that at the core of this contrast is a philosophical difference on how best to improve students' writing. That is, the professors seemed to perceive that instruction in grammar and writing mechanics plays an important role in improving students' writing, which is a significant theme in this study's findings as presented by the professors' comments earlier in this section. In contrast, the mandate of the writing centre reflects a confidence that student writing will improve by facilitating their participation in discussion about their assignments. This view is supported in the writing centre literature that described the most helpful writing tutors as those "who not only listen but draw them [the students] out, ask them questions they would not think to ask themselves" (North, 1984, p.440). Furthermore, in regards to the tutors being under qualified for the job, Bruffee (1984) informed us that "students work tended to improve when they got help from peers ... collaborative learning, it 
seemed, harnessed the powerful educative force of peer influence that had been--and largely still is--ignored and hence wasted by traditional forms of education" (p.638). The Importance of Writing

All of the professors concurred that writing is the predominant form of academic discourse; a representation of one's self; and a prevailing form of communication in the world. Many of the professors asserted that students do not recognize the significance of writing in either the academy or the world at large and based their opinions on the students' written work, which they felt displayed limited writing skills and therefore, indicated a lack of effort towards, interest in, and belief in the value of writing. The professors claimed that they attempted to deliver the message of the importance of writing throughout their courses in an effort to help students to improve writing. For example, Professor Johnson tries to get her students to "understand that writing is important. Many of them come thinking that it just doesn't matter" (February 12, 2009). Professors Andrews stated the following:

It's critically important that they develop writing skills, for practical reasons for one thing. They will be asked in their later years to write papers. It is a fantastic way for students to learn as well too. It also helps them develop their critical thinking skills. And as a life skill or as a professional skill it is incredibly

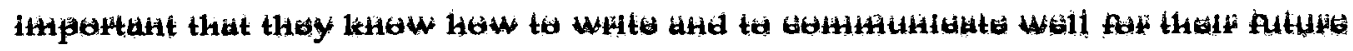
jobs ... so it is a reflection about their ability to express themselves in thoughtful and structured ways. This relevance should be communicated to students [as they don't seem to be aware of it]. (February 10, 2009) 
Professor Simmons added: "Part of my role is to be just a reality check for the students who don't know that they write poorly and ... don't know ... [the importance of writing]" (February 10, 2009).

Critical Reading Skills

All of the professors overwhelmingly agreed that "critical reading, writing and thinking are indivisible from each other" as Professor Johnson asserted (February 12, 2009). They acknowledged that a large majority of the students did not have the opportunity to practice critical reading skills at high school and, therefore, it is a significant challenge for many students to read, understand, and make use of academic texts. Despite their acknowledgement of the compelling connection between reading, writing, and thinking, the majority of the professors in this study do not purposefully design their assignments to capitalize on this understanding. Some of the professors actively engage their students in critical reading opportunities through structured analytical and research assignments, and others provide guidelines for critical reading that they hope will elicit the ability to critically read in an attempt to "help students develop skills they may need later at university or in the workplace" as Professor Sinclair stated (March 17, 2009).

Having said that, the professors reported that they explicitly encourage their students to read and even discuss the linkage between reading and improved writing production, but, as Freedman (1993) informed us, although reading is a necessary prerequisite for the development of writing abilities, "reading alone is not enough" (p.238) and comprehension of motive, responsiveness, and context of texts are further requirements for the development of writing competence. 
Although this study does not reveal the reasons for this apparent disconnect between the professors' acknowledgement of the symbiosis between reading, writing, and thinking and the lack of constructive assignments that reflect this connection, it may be rooted in a lack of awareness of teaching writing on the part of the professors. It is one thing to recognize the existence of a particular phenomenon and quite another to know how to effectively execute its usefulness.

Personal Approach

Professor Johnson insinuated that much of first-year students' writing difficulties stems from "a tendency for a personal approach to writing, filled with opinion and ambiguity rather than an intellectual one that is objective and specific" (February 12, 2009). She was, therefore, adamant that students needed to receive explicit rules on what and how to write. She clearly proclaims to her class what they cannot write about: "I forbid them to write about their feelings. They can't say 'in my opinion,' 'I feel that' or 'I believe that"' (February 12, 2009), as she believes using this vocabulary limits the students' thinking and reinforces the personal and narrow approach to writing. Professor Andrews added: "They tend to write in colloquial ways ... and they're not used to formal thought ... decoding everything they read through their feelings and opinions leads to thinking and writing in a narrow manner that is steeped in colloquialisms and loose ideas that are neither elaborated on nor supported by the literature" (February 10, 2009).

The professors linked the students' tendency to use a personal approach to writing with the five-paragraph essay that they learned in high school, which they consider too limiting for presenting ideas at university. Professor Johnson actually considers it to be harmful. He stated: "I have a kind of specific agenda that I share with many of my 
colleagues which is to un-teach the five-paragraph essay ... and to develop broader, more specific skills dealing with more specific arguments" (February 12, 2009). Other professors are not as restrictive and use the five-paragraph essay as a base from which to introduce the students to a more critical mode of thinking and writing. For example, Professor Sinclair helps his students to expand on their ideas in their essays by "practice[ing] active reading and summarizing ... [and] look[ing] for the main ideas and supporting details ... we flesh out their papers" (March 17, 2009).

\section{Students' Writing Samples}

The students writing samples were examined for comparison of grades in first and second year, professors' feedback styles, and areas of strength and weakness. In three out of the five cases (Alana, Danielle, and Paul), the writing samples from first year compared to second year reflected overall improvement in both their actual grades and the DELNA ratings that I applied to their papers (See Appendix F, p.119). In two cases (Ryan and Sarah), it did not appear that the quality of papers improved. In Ryan's case, he received an $\mathrm{A}$ - in the first year and a $\mathrm{B}+$ in the second year. He attributed his lower mark on his second-year paper to situational factors such as shortage of time due to multiple assignments that he was working on, lack of interest in the topic, and lack of editing due to late night writing. He reported that this lower grade was not indicative of

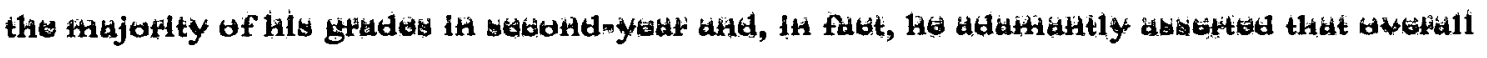
his writing had improved in second year as compared to first year. In Sarah's case, she received an $\mathrm{A}+$ in the first year and an $\mathrm{A}$ in the second year. She claimed that she was not interested in either the assignment topic or the course and wrote the second-year paper in one night exerting much less effort than her norm. 
In addition to a shortage of time due to multiple assignments and lack of interest in the assignment topic, another factor that might influence grades is the semester that the student had written the paper. That is, a paper that was written in the first semester of the first-year may be written less well than a paper written in the second semester of that same year-- assuming it is within the same course with the same professor (Note: the majority of first-year courses in this university are full year courses). We can see these results with the papers from Danielle and Paul, that were written in the first semester of first year, and which scored the lowest out of all the students' papers, and then their writing significantly improved on their second-year papers. Underlying this argument is the premise that practiced production leads to improvement, which is supported by Elbow's (1991) assertion that "no one can learn to write well except by writing a great deal" (p.136) and that, according to Freedman (1993), "learners must also be 'pushed' to produce meaningful discourse in authentic contexts through appropriate assignments and with appropriate feedback" (p.247).

As an additional possible influence on students' performance on written assignments, it is important to consider the effect of disciplinary familiarity. In only one student's case (Paul), the two papers were from the same discipline and, in this case, Pall's dodond-your papor reodivad an 'A' whoreas his first-yoar papar had roceivad a. 'C'. We do not know if gaining disciplinary familiarity was the reason that Paul wrote more competently in second year because the other two students who improved from first to second year (Alana, Danielle) did not submit pairs of papers from the same discipline. The effect of familiarity with disciplinary discourse on a student's academic performance is elaborated on in the Discussion section. 
Although there was a wide range in professors' feedback styles on the students' papers, the feedback was often brief and non-constructive, as the students had claimed during the interviews. I classified these feedback styles as follows: (1) grades without comments, (2) numeric rating scale based on form presentation with an accompanying mark, (3) focus only on mechanics, (4) focus only on content, (5) compliments or criticism only, (6) vague and abstract comments, (7) corrections in the text, (8) only comments at the end or (9) a combination of (7) and (8), and (10) constructive feedback focused mostly on content development, yet attentive to mechanics with comments both in the text and at the end. (See Appendix G, p.120 for an illustration of feedback styles on the students' papers modeled on the DELNA scale).

The professors' claims that first-year students struggle with the mechanics of writing (see the FORM section on DELNA, Appendix F, p.119) and use a personal approach in their academic writing (see CONTENT section, Appendix F) were not reflected in these writing samples. In four out of five of the cases (Sarah, Danielle, Paul, Ryan), the students' ratings in both of these areas were either higher or equal to the ratings in the areas of organization, cohesion and style (see FLUENCY section on DELNA, Appendix F). 


\section{Discussion}

The findings of the study provide us with a glimpse of first-year students' writing needs as perceived by both first and second-year students and their professors and which are reflected in the samples of their writing. There appears to be both similarities and differences between the students' and professors' perceptions, which were presented thematically in the previous section. I further categorized those themes into three overarching themes that allowed me to identify the underlying issues of the students' and professors' concerns. These overarching themes are presented below:

(1) Communication. Opposing students' and professors' perceptions of the writing needs of first-year students appear to be a result of different interpretations of the language being used in the classroom. These differences may be based on the professors' tacit knowledge of disciplinary discourse, which the students are not familiar with, yet this discourse is being used by professors in their communication with the students. The perceptions that differ between the professors and the students, which I have previously identified, are the perceptions of (a) The importance of writing at university and (b) Explicitness in writing instruction, which is divided into the three sub-themes of writing mechanics, clear expectations for assignments, and constructive feedback on assignments.

(2) Meaningfulness. Students perceive that in order to maximize their learning, they need to understand the meaning of their assignments in relation to other assignments, the course, and the program they are in. Some of the professors perceived this same need and reported the use of scaffolding as a method of bringing meaning to their assignments for the students. The students also perceived a need for creativity in their writing at school. 
(3) Transition. The move from high school to university is a significant transition for students and the five-paragraph essay, disciplinary and genre awareness, and writing support have been identified as important themes regarding this transition. This suggests that writing competence is central to first-year students' successful transition from high school.

In order to develop a better understanding of students' perceptions of their writing needs at university, the overarching themes of Communication, Meaningfulness, and Transition will be considered through the theoretical framework of Rhetorical Genre Studies and self-efficacy theory, as well as theory from the field of academic writing studies will be drawn on.

\section{Communication}

The professors and students in this study recognized the importance of writing at university and perceived the importance for explicit writing instruction as a way to help students with their writing at university. Yet students and professors meant something different by this. The professors proposed that first-year students did not understand the importance of writing at university, which lead to poorly written papers, and suggested that students required explicit instruction on the mechanics of writing. The professors perceived that if students could gain knowledge in both of these areas, their writing abilities would take a great leap forward. In contrast to the professors' beliefs about the students not perceiving the importance of academic writing at university and requiring explialt instruetion in the meehanles of writing fin order to inprove th thelp writting competence, are the students' perceptions. First, they unequivocally acknowledged the importance of writing at university and second, rather than needing instruction on writing 
mechanics, as they claimed they learned this in high school, they perceived needing explicit instruction regarding assignment expectations and explicit feedback on their assignments. In response to these perceptions, the professors did not report any of the above as issues that might affect the students' writing. Perhaps this was because they did not perceive their assignment expectations to be unclear, their feedback to be nonconstructive or their assignments to appear meaningless to the students.

Initially I was stumped when pondering the reasons for these differences in perceptions between students and professors. But then I was unexpectedly invited to present my research findings at a departmental staff meeting on campus. During the presentation, some of the faculty members seemed surprised by the findings of my study that showed that, to students', assignment expectations were often difficult to understand, seemed to lack an opportunity for creativity, and were not particularly meaningful. In response to hearing my report on these perceptions, a few seemingly discouraged faculty members asked the following questions, regarding the students: "Don't they know that academic writing can be creative?", "Don't they like anything about writing?" and perhaps most poignantly, "Don't they know our job is to help them succeed?" It was after hearing these questions that a reason for the different perceptions between professors and students occurred to me. It appears to be based on a lack of effective communication

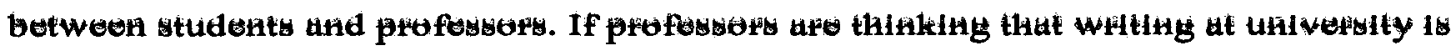
creative and meaningful, yet students do not perceive it that way, perhaps it is more to do with how the assignment expectations and assignment feedback are presented within the course context and communicated rather than with what the assignments are. 


\section{Disciplinary Discourse}

It is therefore conceivable that this observed communication rift between professors and students is a reflection of different interpretations of the language used in the classroom. That is, the professors may be using language that is interpreted by students as conveying a different meaning than the professors had intended it to have. This type of language potentially interferes with the professors' ability to promote learning amongst their students. Ballard and Clanchy (1988) and Hounsell (1988) expanded on this issue by acknowledging the existence of a range of ideas and beliefs within academic disciplines, which determine what may be said, and the ways in which it may be said. These ideas and beliefs are enacted through genres, "a distinctive category of discourse" (Swales, 1990, p.68), because "genres are how things get done, when language is used to accomplish them" (p.40). Furthermore and quite critical to understanding this observed communication gap, Ballard and Clanchy and Hounsell suggested that these ideas and beliefs may be tacit, and therefore unlikely to be discussed directly between faculty and students. Strachan (2008) provided an example of this tacit knowledge from an interview with a faculty member during the process of designing a new writing curriculum at Simon Fraser University. This faculty member, a historian, did not recall being taught to write: "I am somebody who understands history and it feels as though it came to me through osmosis or something" (p.142). Strachan summarized: "For all the faculty interviewed, it seemed that the process of the acquisition of their particular disciplinary discourse was so embedded in their apprenticeship in the discipline that it was invisible to them" (p.142). The notion of disciplinary knowledge being tacit is expressed by academic writing researchers McCarthy and Fishman (1991), who 
recognized "how hard it was for us to articulate our differences because so much of what we know is tacit" (p.460).

As opposed to the professors' possession of disciplinary discourse, as stated in the example above, first-year students are without this discourse and often without disciplinary awareness. If the professors use mostly this discourse to communicate with their students, it might seem as if they are communicating in a different language. It is therefore important to consider disciplinary discourse as a primary possibility for the communicative disconnect between professors and students. Petraglia (1995) explains this idea further in regards to clear expectations for assignments:

When students complain of not knowing what the assignment really requires, they are not so much suggesting that they are bewildered by the complexity of the rhetorical problem placed before them as much as signaling their anxiety and frustration vis à vis the curious task environment [which an unfamiliar university classroom places them in]. (p. 91)

It seems highly relevant to the understanding of this observed lack of communication to state that this unfamiliar environment, as referred to above, is steeped in disciplinespecific discourse, which is foreign to the students, as was confirmed by the first-year students in the focus group of this study. The absence of discourse awareness can drectly lead to comprohension problems for first-year studonts us, according to Bruffee (1984), "any effort to understand conversation requires us to understand the nature of community life that generates and maintains conversation [emphasis added]" (p.640). The community we speak of in this instance is that of a particular academic discipline which, as Swales (1988) informs us in his definition of discourse community, "is 
composed of those who share functional rules that determine the appropriacy of utterances" (p.211). McCune (2004), drawing on Taylor, brings the discussion presented in this section full circle when she adds that as a result of students being uncertain about the meaning and usage of the discourse, "sometimes, students' difficulties with these issues can be masked, as problems mastering the academic discourse can manifest themselves in surface difficulties with grammar and syntax" (p.277).

In adding further understanding to the premise of disciplinary discourse having an effect on communication between professors and students, we might first look at Bakhtin (1986), a founder of genre theory. His concept of addressivity of genres--the ways in which the discourse is shaped by the perceived hearer/reader--seems crucial in a classroom environment, as it leads us to understand that the meaning the students can acquire is based on what they perceive is being communicated to them. In the case of assignment expectations, it is easy to see how students can become confused if they do not understand the language that is being used to explain the expectations. Furthermore, Bakhtin explained that the way a speaker/writer chooses to express ideas is based on whom the speaker/writer is talking to and "how the speaker (or writer) senses and imagines his addressees" (p.95). Thus, we would expect that the professors would use discourse that the students could comprehend in order for the students to perceive the assignment expectations and feedback on their papers as the professors had intended.

Aside from the possibility that the professors are not aware that they are using disciplinary discourse that the students do not understand, as stated above, there is another possibility for consciously not using discourse that the students understand. Strachan (2008) revealed this reason within a response from a professor whom she 
interviewed regarding the question of vague assignment expectations: "I could explain until I was blue in the face, they still don't get it" (p.124). In this case, not only was the professor reportedly unaware of the students' concerns that his assignment expectations were not clear but also seemed to lack confidence in the students' ability to understand the assignment no matter how much he broke it down. This thinking may be depicting a harmful cycle where efficacy beliefs based on situational factors (e.g., the students' performance on assignments) may determine one's perception of the efficacy of others (e.g., the professors' beliefs about students' efficacy) and, thus, a response to these beliefs may be initiated and acted upon as if the beliefs were factual. If this premise were accurate, that would involve the professor perceiving that despite his best explanations the students could not understand his assignments (based on their questions or their finished work) and therefore, he decided it would be in vain to alter his assignment expectations in any way, leaving the students in continual confusion and the professor in frustration. This, of course, is just my speculation that deserves attention in future research.

While students are struggling in acquainting themselves with a new discipline and many of the genres this entails, there is a danger of them drawing on previously acquired knowledge that may be applied inappropriately. Solfefficacy theoriats, Linnenbrink and Pintrich (2003) assert:

There may be occasions where students are very confident in their prior knowledge and this confidence interferes with their learning ... as they have strong efficacy beliefs that they already know the content to be learned... [which] may lead the student to be less engaged in learning new ideas because 
they think they know it already. If their prior content knowledge is appropriate, then this is not a problem. However, there are many cases where students think their content knowledge is appropriate, but in fact ... [it] is not representative of the normative understanding in the discipline [emphasis added]. (p.130) It is evident that this situation could result in inhibited learning for students. For example, if a student who was actually weak in grammar and mechanics, but did not anticipate having any difficulties in this area (as the students in this study claimed) and, therefore, had not paid attention to any new instruction or asked for help, he may then have a higher likelihood of submitting a paper with multiple problems in this area. Bazerman (1997) and Russell (1997) have suggested that when newcomers interpret new situations based on perceptions of genres that they have learned elsewhere, they often do so inappropriately, as they are not aware of the situatedness and disciplinarity of the new situation.

Disciplinary discourse is not acquired overnight and habitual exposure within a community is required to gain familiarity with the discourse (Swales, 1998; Berkenkotter \& Huckin, 1995). Then, one may ask how first-year students, who have not had habitual exposure to the disciplinary discourse, are supposed to acquire the genres belonging to it enough to understand their assignments and feedback on those assignments. This is a partioularly inportant quastion for profosore to undoratand badaudis findinge in thit atudy reveal that acquisition of disciplinary discourse appears to be helpful in order for students to understand their assignments and feedback on their papers. Although it is not the mission of this thesis to provide pedagogical instruction, in keeping with previous strategies of this paper, it is within the mission to provide various insights from the field 
of study. Therefore, I can offer constructs from RGS that might help students with limited disciplinary discourse to understand their assignments and corresponding feedback. First, it might be helpful if the students were able to perceive their assignments and feedback on their papers as particular genres within the context of their classroom. Second, they could learn that their classroom represents a valid social context with particular classroom genres (assignments) that are situated in it (Freedman, 1993). They could then learn the range of these genres and how these genres are interrelated (Bazerman, 1994, 2004), have a purpose, audience and are social actions (Miller, 1984, 1994). Of course, this cannot happen without the professors facilitating this learning. I started this section by discussing the different perceptions that students and professors had regarding the importance of writing at university and explicitness in teaching writing mechanics for assignment expectations, and on feedback on students' assignments. I then used these different perceptions to explain a communication gap between professors and students, which is possibly steeped in the professors' use of disciplinary discourse in the classroom. I now end this section with some insight on explicit instruction and how students might acquire disciplinary discourse.

\section{Explicit Instruction}

Although according to the study results, it appears that students want assignment instructions and feedback on their papers communicated explicitly, and that professors feel the need to teach grammar and writing mechanics explicitly, Freedman (1993) suggested that offering only explicit teaching may be unnecessary, usually impossible, not particularly useful for learning, and also potentially harmful. For an example of explicit teaching being possibly unnecessary, one can review Freedman's research on a 
small group of students in an introductory undergraduate law course who were able to produce distinctive written genre without any explicit guidance. Freedman explains that "the fluid and dynamic nature of most genres [makes it difficult] to specify or articulate with assurance the rules for such genres, except possibly historically and in retrospect" (p.232). It is important to note that Freedman recognizes there is validity in explicitly teaching some "overall features of format or organization ... and a limited set of rules regarding usage and punctuation" (p.237), but only if it is done to promote "the experience of the ways of thinking or procedures of handling concepts and styles of deployment or argument, that are employed in the professional domain" (Freedman \& Medway, 1994, p.14).

The students in this study experienced a transition from being confused first-year students, who were unsure of how to interpret and complete their writing assignments, to more secure second-year students, who had gained a degree of confidence in how to employ disciplinary discourse. I wondered if they had received explicit instruction in order for this transition to occur and when I had asked them this question, they could only acknowledge that this transformation had occurred, but did not know why or how. For example, when I asked Paul how he learned how to write papers for his major, Philosophy, and why his writing improved from first year to second year, his response was simply, "I couldn't tell you ... just dolng It over and over. Uneonsuleusly you lourn what to do" (February 27, 2009). Danielle reported: "In second year [is] where I started to figure out ... how I should be doing it [writing]. I don't know where that transition kinda occurred maybe it was osmosis but I'm getting it now ... my writing skills have exponentially improved" (February 26, 2009). It is important to note that for both Paul 
and Danielle, their samples of writing that they provided for this study showed significant improvement from first year to second year.

When considering what influenced the students' increased writing competence, it may be valuable to consider the impact of growing familiarity with disciplinary discourses. Perhaps the students' experiences were similar to Freedman's (1993) law students whose writing abilities "naturally evolved out of the disciplinary conversation" (p.239) and who were not consciously aware that they were gaining disciplinary language. Some professors in this study indicated that gaining disciplinary language along with maturity and repeated exposure to assignment styles were catalysts for students' improvement in their writing and others believed that an effort on the part of instructors to scaffold assignments and explicitly impart knowledge accounted for the improvement in the students' writing. In addition to the idea of familiarity with disciplinary discourses, self-efficacy theory also provides us with some ideas on what contributes to students' increased writing competence. Pajares and Valiante (2006) refer to such researchers as Graham, MacArthur, Schwartz, Page-Voth, Schunk, and Swartz who revealed that "Self-efficacy and writing competence increase when students are provided with ... specific strategies they can use to improve their writing as well as regular feedback regarding how well they are using these strategies" (p.163). Examples of these strategies include concept maps, outlines, and multiple drafts. A detailed discussion of these strategies is beyond the scope of this study.

\section{Meaningfulness}

The majority of students in this study claimed that they were often unsure of the purpose of their assignments, how these assignments were connected to each other, the course, 
and the program they were studying. Furthermore, they identified perceived meaningfulness in their assignments as positively connected to their performance at school. The professors in this study acknowledged perceived meaningfulness as a relevant component to the students' learning experience, yet I question whether the professors truly embraced this concept, since the students reported a perceived lack of such meaningfulness in many of their assignments. On the other hand, the professors might have embraced the concept of meaningfulness for their assignments and this might be another example of a communication gap between the professors and the students as discussed in the previous section. Theoretical insight regarding the students' perceived need for meaning in their assignments can be gleaned from several sources. Studies conducted within the RGS framework report that writing assignments need to be purposeful and placed in an identifiable context in order to be understood and produced with a sense of competence (Artemeva, 2005; Freedman \& Medway, 1994; Hunt, 1993; Paré, 2007). Reither and Vipond (1989), theorists in writing studies, reported on setting up research projects that provided "real audiences who have real needs" (p.265) for their students to participate in. They claimed, "we learn to write by using writing, our own and others', to achieve genuine ends" (p.866). Therefore, how can the professors' emphasis on correct form, as was discussed in the previous section, rather than on meaning lend to the students' understanding of the importance of writing at university? Furthermore, a study by Sommers and Saltz (2004), echoing Miller (1984), reported that when students perceived meaningfulness in what they were writing about, they recognized that "writing is not an end itself but is a means for discovering what matters" (p.146). Finally, self-efficacy theory purports the positive relation between self-efficacy 
and perceived value (Pintrich \& Schunk, 1996). That is, if the students are able to discover something important, they will attribute greater value to this knowledge and their self-efficacy will then increase, possibly leading to increased opportunity for developing academic competence.

Having said that, two out of five professors (Professor Andrews and Professor Sinclair) acknowledged the importance of perceived meaningfulness in a learning environment and reported that they purposefully design their assignments in a scaffolding manner so that each assignment builds upon the previous one in an attempt to create relevance for the students. Professor Sinclair stated: "We practice active reading... [with] a framework ... that makes connections between what you read and other readings, other concepts and what you do in other courses ... and by making those connections ... you reach a deeper level of understanding" (March 17, 2009). Professor Andrews commented: "Often the smaller assignments that I use are smaller assignments that can then be incorporated into the larger papers" (February 10, 2009). Scaffolding, as introduced and explained by Wood, Bruner, and Ross (1976), is closely related to Vygotsky's more general theoretical concept of Zone of Proximal Development (1978),

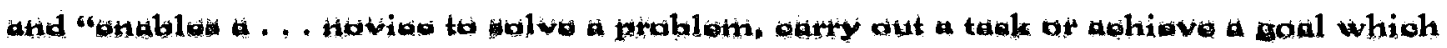
would be beyond his unassisted efforts" (p.90). Rose, Gray, and Cowey (1999) illustrated an example of scaffolding in a study where "indigenous school children were supported to read complex texts ... that are well above their normal independent reading level" (p.10) and afterwards, their writing ability was affected in much the same way. Recognizing the value of situating meaning in learning and drawing on RGS, Devitt (2004) suggests teaching genre awareness "for students to understand the intricate 
connections between contexts and forms ... and having learned how to perceive purpose behind form, the learner can discover the purposes behind the particular forms" (p.197198). It seems that Devitt is referring to students' capability of learning in one scenario and then being able to apply the learned concepts in another, or the transfer. In the case of the study presented in this thesis, perhaps teaching the students genre awareness in their first year at university might be advantageous to them as it might help them to comprehend the existence of differing genres within academic disciplines and, therefore, help them anticipate writing differently in each discipline. This anticipation may then position the students to more openness towards new knowledge that is presented to them. But perhaps it may not. There is the case of Sami (Aremeva, 2005), a novice engineer, who when having to prepare a proposal "relied more on what [he] learned at school and [his] other experiences" (p. 403) than on what his company was doing. His purpose for writing his own proposal was that he wanted to show his initiative to the senior staff. Sami's decision to write his own proposal reflected a premise of the situational perspective of self-efficacy theory, which Linnenbrink \& Pintrich (2003) explained as a variation in "self-efficacy judgements for similar tasks . . . as a function of . . [ [the] individual, task conditions, or environment" (p.122). That is, Sami made a judgement about his ability to act based on the identified situational factors of wanting to impress his supervisors. Such judgement is considered by Bandura (1977) to be "a better predictor of behavior toward unfamiliar threats [new assignment/situations] than [is] past performance" (p. 211).

Taking the premise of genre awareness to a practical level, Downs and Wardle (2007) designed a replacement courge for first-year composition, that they called 
Introduction to Writing Studies. This course "seeks to improve students' understanding of writing, rhetoric, language, and literacy" (p.552) and is "about how to understand and think about writing in school and society" (p.558). Through researching, reading, and writing about the topic of writing, Downs and Wardle believe the students will be better poised "to address issues of specialized discourse within specific academic disciplines" (p.558). Having said that, their findings from their pilot project (Wardle, 2007) indicated that the students were able to "engage in meta-discourse about university writing in general" (p.73), however the students did not seem to have the need for this knowledge in their other courses. The students in Wardle's study explained that the writing they did in their other courses, both in first and second year was very easy, e.g., summaries, which did not require the careful preparation and research that they had done in Downs and Wardle's class. The argument in both Devitt's and Downs and Wardle's cases seems to focus on preparing first-year students for the diverse academic world they have just entered by providing them with knowledge about writing. I am anticipating that it is from this knowledge that the researchers hope that students will be better prepared to learn disciplinary discourse and genres. These are valiant attempts to help students in acquiring a stronger sense of meaningfulness in their learning environments but it appears that current research is inconclusive and further research needs to be done in this area. Creativity

The students perceived their assignments as meaningful if they allowed for creativity, and first-year student participants in this study, in particular, did not perceive any form of academic writing to be creative. Perhaps it is difficult for students to recognize the allowance of creativity in their academic work, as they must adhere to 
"conventional forms preferred or prescribed by a discourse community" (Coe, 1994, p.160). Unless professors communicate this potential to students, it may be difficult for students to perceive that there is room for creativity in academic writing. In other words, professors may be better off by explaining to students what they mean by creativity. Devitt (2004) tells us that creativity can be achieved by teaching genre awareness where students can "discern both constraints and choices that genres make possible" (p.198). She advocates informing students that they can revise existing samples of genre, "see how far they can stretch a genre ... how much creativity and variation is possible within existing genres" (p. 200). Bakhtin (1986) offers another way of perceiving creativity in writing at university, which is through the words we choose: "We select the word because of its meaning, which is not in itself expressive but which can accommodate ... our expressive goals in combination with other words" (p.86). It might be quite encouraging to students to consider creativity in this way and might give them a whole new perspective from which to view their writing assignments.

\section{Transition}

First-year students experience a significant transition when coming from high school to university, adjusting to these differences and incorporating these differences into their writing assignments. There are many options to support students through this transition and ultimately help them to acquire greater writing competence. These are discussed below.

\section{Differences between High School and University}

In this study both the students and the professors acknowledged a significant transition for first-year students coming from high school and suggested that this 
transition places the students in a deficit position regarding their ability to write at university. The professors found it frustrating that the students had been taught to think and consequently write in a limited and personal manner, and the students found it frustrating that at high school they spent a lot of time perfecting a writing form that is not acceptable at university. In fact, Wallace and Wallace (2000) harshly refer to students in their first-year composition classes as "functional academic illiterates who have not the first idea of what it is to be considered a reader, let alone think about how a reader might respond to their attempts at written communication" (p.79). Yet, Shaughnessy (1977) offered a more compassionate explanation about first-year students' writing and reading abilities: "Basic writers write the way they do, not because they are slow or non-verbal, indifferent to or incapable of academic excellence, but because they are beginners and must, like all beginners, learn by making mistakes" (p.5).

Five-paragraph essay. Albeit, the reasons for this apparent disconnect between the public school system and the university system can be endlessly pondered and even blame can be laid for the students' lack of preparation for university, or more productively, strategies can be developed to build on the students' knowledge that they have acquired prior to entering university in an attempt to achieve further learning for them. For example, considering that the five-paragraph essay might be a reasonable attempt for organizing thoughts for constructive purposes, the value of this genre can be acknowledged and rather than deconstructing it and intentionally removing it from the students' repertoire, and professors might perhaps exploit it and build upon it. Devitt (2004) supports this idea by referring to Jamieson's work on antecedent genres and reports that "the historical evidence suggests that people use familiar genres to act within 
new situations ... and existing genres serve as powerful antecedents in shaping newly emerging genres" (p.204). Devitt further explains that first-year students will encounter "some situations and contexts that significantly overlap those of the new genres they need to acquire" (p.207) and will naturally use genres they learned in high school, such as the five-paragraph essay, to tackle university assignments.

While participating in the activity of acknowledging their prior knowledge of genres and incorporating new genres into their repertoire of existing genres, the students may move from perceiving the five-paragraph essay as an effort in vain to seeing the continuity in their educative experience and thus attain greater meaningfulness and ultimately greater learning in their university experience. Likewise, the professors' frustrations may be reduced once they acquiesce to this possibility and then realize how to use students' prior genre knowledge for building on this resource, ultimately influencing more effective learning for their students. For example, a professor may deconstruct the genre of a five-paragraph essay and then lead students to the understanding of genres of academic writing in her discipline. Devitt suggests that 'teachers can ... a aid their students' acquisition of the genres they require students to produce . . by providing multiple samples of each assigned genre . . . and showing as wide a range of creative choices as possible" (p.208).

Academic Writing as a Single Entity. Since the students are enduring a transitional time from high school to university, it should be expected that as novices to the environment, they would need to be exposed to an abundance of new concepts. Firstly, the notion of academic writing being a single entity is not unreasonable to expect from these students. Most of the first-year students in this study did perceive writing at 
university this way which might be reasonable considering that, according to Roe and den Ouden (2003), academic writing "has been defined loosely, to mean writing that demonstrates such qualities as critical thinking, intellectual curiosity, and a certain elegance or sophistication" (p.xiii). Nevertheless, this definition by itself is incomplete and may therefore pose harm to the novice students by encouraging them to think in a limited manner, unaware of disciplinary differences that determine how written conversations are joined. Rather, it might be helpful for students to become aware that as Elbow (1991) exclaimed, “We can't teach academic discourse because there's no such thing to teach. Biologists don't write like historians. This is not news" (p.138). Furthermore, Cooper and Holzman (1989) concluded, "There seems to be no reason to assume that there is a general academic discourse community, no strategies of inquiry or discourse practices that all the disciplines seem to hold in common" (p.49). Finally, Downs and Wardle (2007) complete the barrage by saying that "more than twenty years of research and theory have repeatedly demonstrated that such unified academic discourse does not exist... [so by] asking teachers to teach 'academic writing' begs the question: which academic writing - what content, what genre, for what activity, context, and audience" (pp.552, 556).

Once the students have realized the delusion of one-ness of academic writing and understood the more expansive notion of writing at university, just like the second-year students did in this study or like Freedman's (1993) law students did, they may be in a better position to absorb knowledge about the diversity of genres, the different purposes and forms that genres envelop, and how this knowledge is directly related to their writting development. 


\section{Genre Awareness}

First-year university is a time of great transition for students, but this is not to say that they arrive empty headed as they have built up a great deal of knowledge from twelve years of previous schooling. It seems, then, that it is the teachers' challenge to ease their students through this transition and recognize, as Berkenkotter and Huckin (1995) assert that "Genre knowledge ... [is] acquired incrementally as students progress through a period of apprenticeship" (p.13). Genre knowledge is regarded by RGS scholars as critical for students to increase their writing competence. Coe tells us that "understanding genre will help students become versatile writers, able to adapt to the wide variety of types of writing tasks they are likely to encounter in their lives" (as cited in Strachan, 2008, p. 122). Once students are aware of genre differences, recognize their repertoire of existing genres, and continue adding to it, they may be in a more advantageous position from which to express and present themselves because, according to Miller (1984), "what we learn when we learn a genre is not just a pattern of forms or even a method of achieving our own ends. We learn, more importantly, what ends we may have" (p.165).

Devitt (2004) argues for teaching students about genre diversity through genre awareness and doing so explicitly. She clarifies this by saying "explicit teaching does not require presentational teaching" (p.198) and argues that "not for teaching the textual features of particular genres, not for the goal of teaching students how to produce texts within particular genres, but rather for teaching genre awareness, a critical consciousness of both rhetorical purposes and ideological effects of generic forms" (p.192). Devitt proposes that students can learn genre awareness through "environmental teaching" as 
identified by Hillocks, where teachers "can most effectively lead students to explore and discover for themselves these [genre] principles, which the teacher then helps to articulate and pushes students to practice" (p.198-199). Gaining genre awareness is a process that will be built upon during the students' years in university.

\section{Writing Support}

In this study, I have observed that first-year university presents a significant transition for students, which seems to directly impact their competence on writing assignments. I also noticed that both professors and students unanimously agree that tangible writing support for students presents a valuable opportunity for students to improve their writing abilities and thus, their assignments. The specific writing support opportunities I examined in this study were the first-year seminar, the First Year Experience program, a first-year mandatory writing course and the writing centre, yet I will restrict this discussion to the first-year seminar as it was, more so than the others, singled out by both professors and students as an "excellent opportunity to develop writing skills” (Professor Sinclair, March 17, 2009).

The first-year seminar is described in the calendar of the university that served as the research site for this study as having small size classes that are specifically designed to help students to go deeper into the topics in the core subject area that are discussed in class or chosen by the students and research them. In such classes students will begin to develop skills in essay writing, critical thinking, problem solving and media literacy. Furthermore, the first-year seminar is intended to "offer students a means of understanding the concepts and arguments of particular fields by writing, under the guidance of disciplinary practitioners, in the very discourses that have produced those 
concepts and arguments" (Brannon, 1995, p.241). Professor Sinclair explained that the first-year seminar is "a great configuration because you do have some content to work with which is the discipline that you want to introduce students to but at the same time you have a seminar format that allows you to design assignments that allows for extended writing" (March 17, 2009). Additionally, as Devitt (2004) asserts, based on Jamieson's work on antecedent genres, "known genres serve as antecedents for writers" (p.204), and teaching genre awareness in the likes of a first-year seminar could serve as "a bridge between genres acquired before and those acquired during and after college" (p.204).

The first-year seminar evolved from the (American) university first-year composition course that was steeped in an assumption from the product paradigm that writing was accessible through learned skills, which were ultimately transferable. Over the past three decades, wide spread recognition has been gaining ground that this program's goals have not been achievable. In referring to the dismal outcome of the traditional first-year composition course, Kerri Morris (2000) stated: "I feel confident in saying that we have failed. Miserably. Most students who pass through our first-year course write no better after the course than they did before" (p.116). Devitt (2004) also attributes a significant reason for failure of this program to "a potential lack of transferability of the general writing skills learned in composition courses to the particular writing tasks students will later confront" (p.202). In referring to the first-year composition course, Downs and Wardle (2007) presented research that "seriously questioned what students can and do transfer from one context to another (Ackerman, Berkenhotter and Huckin, Carter, Diller and Oates, Kaufer and Young, MacDonald, Petraglia, Russell)" (p.552). 
Shaughnessy (1977) accounted for this failure by attributing it to the lack of writing opportunities in the traditional composition courses: "For only as a writer, rather than as an exerciser, can a student develop the verbal responsiveness to his own thoughts and to the demands of his reader that produces genuinely mature syntax" (p.89). Others have critiqued the non-contextual format of the curriculum. In this regard, Brannon (1995) explained: "Reading and writing are not mere technologies enabling the transfer of information, but are socio-cognitive practices enabling critical inquiry about and intervention in 'the world' on one's own behalf ... [therefore in order to enact effective learning] one [must] believe that writing and reading are not prior to the understanding of content but integrally connected with it" (p.244). In response to this failure of first-year composition, many universities, either as a campus, faculty, or departmental initiative, have been aiming to replace the composition course with programs that are discipline specific and writing intensive, such as the first-year seminar. In this study, Professor Johnson revealed that her department has already "designated certain courses 'writing attentive' where the students are typically given multiple writing assignments with continual in depth feedback and have to meet writing challenges that are agreed upon [by the department]" (February 12, 2009).

Although the first-year seminar has been recognized as an advantageous learning

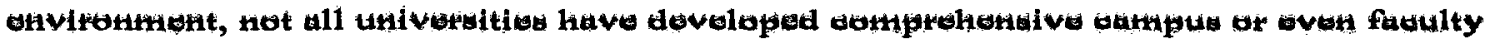
wide implementation plans and, therefore, when it is left up to the individual professor how to teach a first-year seminar, there is not always consistency, which is the case at the university in this study. Some of the professors seem to be more aware than others in how to structure a first-year seminar to best meet the needs of the students and therefore, 
unequal experiences result for the students. Second-year student Danielle experienced this inconsistency and reported the following:

[In one first-year seminar], I couldn't figure out what he (the professor) wanted from me or how to deliver it. And so it was a complete exercise in frustration... [yet my other first-year seminar] was very tangible and I wouldn't say they just handed us the information, they presented it in such a way that we were still working, like we weren't being spoon fed but it was easier to see the relationship between what we were studying and what we were to produce about that study. (February 26, 2009)

It therefore seems that an overarching university or at least faculty wide implementation plan for the first-year seminar needs to be created or there may continue to be inconsistency in the output and thus in the potential learning that occurs. On the other hand, despite the greatest implementation plan, it may be that the inconsistency regarding the teaching of first-year seminars is reflective of what Shaughnessy (1977) tells us: "programs are not the answers to the learning problems of students but teachers are and .. . good teachers create good programs, ... the best programs are developed in situ, in response to the needs of individual student populations" (p.6). Gorman, Gorman, and Fulwiler (1986) at Michigan Tech University support this unprecedented value of good teaching: "We continue to believe that faculty are the dominant influence on the mode and quality of education at a university and that, consequently, their attitudes and practices have direct bearing on student writing and thinking" ( $p .65)$.

It is interesting to note that despite literature, peer, and student support for firstyear seminar styled courses over the previous skills based courses, such as first-year 
composition, there still exists some persistence for inclusion of the latter into the university curriculum. In this study, Professor Simmons stated:

It'd be nice if there were some... I don't know ... if students were required to take a course where there was writing or something like that ... [to] help students with just basic grammar ... like an English/writing course [that] is required firstyear. (February 10, 2009)

This section has discussed the ongoing transition from first-year composition courses to the first-year seminar in the university environment. The first-year seminar differs from the skill based composition course as it is intended to provide small classes where firstyear students receive extended writing and research opportunities in a discipline specific context.

This discussion has presented the writing needs of first-year students based on the perceptions of first and second year students and their professors. These perceptions, which are both contrasting and similar, have been categorized into the three overarching themes of communication, meaningfulness, and transition. Within the theme of communication, perceptions on the importance of writing, explicitness in writing instruction, teaching grammar and mechanics, clear expectations for assignments, and importance of feedback on assignments were discussed. The premise of a obmmunioation gap balagd an different intergretatione of languago uaed in the elageroom was presented as the underlying reason for the contrast in perceptions between students and professors. These suggested different interpretations of language are based on disciplinary discourse awareness. Within the theme of meaningfulness, students' perceptions on their need to construct meaning from their assignments for a more 
beneficial learning experience, is highlighted. Specifically, the students' perceptions about the relevancy of their assignments in relation to other assignments, the course and the program they were studying, were presented as critical to the students' learning experience. In addition, students perceived the ability for creativity in their assignments as an important factor for interpreting meaningfulness in their assignments. Within the theme of transition, the professors' perceptions on students' writing needs were based on differences between high school and university, specifically the five-paragraph essay and recognition of disciplinary differences. In addition, the value of teaching genre awareness and the benefit of a first-year seminar were presented as means to supporting students' writing competence.

Despite the transition that first-year university presents for students, it is still within the power of each individual to determine how they will fair through this transition. Linnenbrink \& Pintrich (2003) explain that self-efficacy theory suggests that "individuals with strong efficacy beliefs are more likely to exert effort in the face of difficulty ... [versus] individuals who have weaker perceptions of efficacy [and] are likely to be plagued by self-doubts when confronted with difficulties"' (p.127). 


\section{Conclusion}

In this chapter, I summarize the findings of the research study presented in this thesis, discuss the limitations of the study, and propose directions for future research. This study focused on the academic writing needs of first-year students as perceived by both first and second-year students and their university professors. The purpose of the study was to compare students' and professors' perceptions, and, therefore, expectations, and to examine if there were changes in the students' writing as the students progressed through their academic studies and gained some disciplinary knowledge in different subjects. Although students' perceptions of their needs may not necessarily reflect their actual needs, understanding their perceptions is invaluable because, as Horowitz (1987) reminds us, what learners believe about what they are learning and about what they need to learn strongly influences their receptiveness to learning. In order to gain further understanding of the effects of students' beliefs on their academic writing competency, Rhetorical Genre Studies in combination with self-efficacy theory was used as the study's theoretical framework. The methodology of the study was based in the qualitative paradigm and the methods were influenced by the constructs of grounded theory as developed by Charmaz (2006). The following overview of the thesis briefly restates the methods used to collect and analyze the data, the theoretical framework used to interpret the data, and the results of the analysis.

In this study I conducted semi-structured interviews with five second-year students who had participated in varying first-year pedagogical experiences; five professors who all taught a first-year seminar and were from different disciplines, and a focus group of nine first-year students who were enrolled in a first-year seminar in a 
specialized first-year pedagogical environment--the First Year Experience program. After transcribing the audio-recorded interviews, I analyzed the data using the coding premise of Grounded Theory (Charmaz, 2006; Strauss \& Corbin, 1990) and used Strauss and Corbin's methods of open coding and axial coding. In addition to the interviews and for the purpose of data triangulation, I collected two samples of writing from each second-year student: one from the first year and one from the second year, to investigate how the students' work compared to their reported perceptions of their writing needs. I analyzed the writing samples using the Diagnostic English Language Needs Assessment (DELNA) rating scale as a guide (Knoch, 2009).

\section{Summary of Research Findings}

The findings of the study indicated that RGS along with self-efficacy theory are valuable tools for understanding the perceptions of first-year students' writing needs. RGS informs us that writing is a meaningful social activity and that, therefore, if professors are teaching writing through the limited confines of form, it may be difficult for students to perceive writing in any other way than as a meaningless singular requirement. RGS also suggests that teaching only form is not an effective way for students to gain writing competence because of the changing nature of genres, which leads to changes in the forms that envelop them and therefore students may be taught one form that will become obsolete in a short time thereafter. Two RGS scholars, Freedman and Medway (1994), explained that there might be some validity in tenching form but only if it is done to promote "experience of the ways of thinking or procedures of handling concepts and styles of deployment or argument" (p.14). Furthermore, 
understanding the breadth of genres allows students to perceive meaning and creativity in their writing.

Self-efficacy theory helps us to understand that students' perceptions about their ability to attain a specific goal--a skill or a task-- influences their behaviour regarding that skill or task (Bandura, 1977). These perceptions are influenced by individuals, task conditions or environmental conditions, such as a new teacher, new type of assignment, or new academic environment, and are considered to be a better predictor of behaviour than past performance. The studies conducted within the framework of self-efficacy theory indicate that students with high self-efficacy have strong perceptions about their ability to attain a specific goal and students with low self-efficacy are likely to have selfdoubts, which may interfere in their ability to attain the set goal (e.g., Bandura, 1986). It is then likely that the majority of the second-year students in this study had fairly high self-efficacy, particularly in their second year at university, as three out of five students improved in their assignments, as was evidenced by their writing samples that I analyzed for this study. Furthermore, self-efficacy theory supports students' perceptions that constructive feedback on their assignments helps them increase their writing competence, and that if students perceive the meaningfulness in a task, their self-efficacy will likely increase, leading to a greater likelihood of goal attainment.

Self-efficacy theory appears to be a valuable tool for understanding students' motivation towards academic competence. Pajares and Valiante (2006) summarize the benefits for professors to understand self-efficacy theory:

Over two decades of research on the influence of self-efficacy beliefs in academic functioning have confirmed Bandura's claim that self-efficacy beliefs play an 
influential role in the choices that students make, the effort and perseverance they exert, and the level of success they attain ... teachers would do well to take seriously their share of responsibility in nurturing the self-efficacy beliefs of their pupils, for it is clear that these beliefs can have beneficial or destructive influences. (p.166)

Other important findings of this study are that the students and the professors have contradictory perceptions of the students' view of the value of writing at university, the value of feedback provided by professors on students' written assignments, and the type of explicit instruction each group perceived as necessary for the students' optimum learning and performance. The analysis of the data has demonstrated that the reasons for these perceptions can be explained as follows.

First, professors and students' opposing perceptions of the writing needs of firstyear students may have been as a result of a lack of communication. Professors seemed to be using disciplinary specific discourse with their assignment expectations that the students were not familiar with and, therefore, students might have interpreted the assignment instructions and feedback on their assignments differently than how the professors had intended them to. These opposing perceptions are particularly clear when professors and students discuss the issues of a) Importance of writing at university, where professors do not appear to perceive students as valuing writing at university, yet the students perceived academic writing to be very important and b) Explicit instruction, where the professors perceived that in order for the students' writing competence to improve, the students had to receive explicit instruction in grammar and writing mechanics, which they could then apply to their papers and thus, produce better work. In 
contrast, the students perceived that they had already acquired a lot of knowledge in the area of grammar and writing mechanics from high school and insisted that in order to improve their writing competence they needed clearer assignment expectations, meaningful assignments, and constructive feedback on their assignments

The analysis of the students' writing samples supported the students' perceptions that--at least, in this study--they did not struggle with grammar and mechanics in their writing. As demonstrated in the findings, in nine out of the ten analyzed samples of academic writing, the ratings, using the preset categories of the DELNA scale, on FORM were equal to or higher than the ratings on CONTENT or FLUENCY. Furthermore, the analysis of the professors' feedback on the students' writing samples supported the students' perceptions that feedback on their assignments was often vague, brief, and nonconstructive. It is interesting to note that in spite of the students' perceptions of limited feedback and unclear writing assignments, three out of the five student participants in this study received between $\mathrm{A}+$ and $\mathrm{A}-$ on their first-year papers that they had submitted for analysis. Therefore, I think it is important to distinguish between what students perceive might help them in their writing assignments versus what they perceive actually hinders their writing competence. In the case of these three students, perhaps what is becoming clear is that the students perceived that more explicit assignment expectations and constructive feedback on their papers may make it easier for them to approach each new assignment but lack of these did not necessarily hinder their performance.

Second, students perceived meaningfulness of thelr assignments to be an important factor for their academic success. Although the professors agreed with this perception, they did not seem to have communicated meaningfulness of the assignments 
to students nor did they create a context (or clearly acknowledge the existing context of the classroom) that would allow their students to see assignments as meaningful because the majority of students did not appear to have a clear understanding of the purposes of their assignments or how these assignments were connected to each other, the course, and the program they were studying in. In addition, the students did not perceive that academic writing allowed for creativity, which lead to the development of their perception that academic writing lacked meaningfulness for most of the students. Options for eliciting meaningfulness in assignments proposed in the past included scaffolding so that students can perceive the connection between assignments, and genre awareness so students can perceive the connections between text and form. More attention needs to be paid to such pedagogical endeavours.

Third, students and professors acknowledged the transition that first-year university students experience coming from high school and perceived that this transition placed the students in a disadvantaged position regarding their ability to write at university as they had seemingly not been adequately prepared for university writing. The difficulties of this transition resulted in frustrations for both the professors and the students because the professors did not feel that they were supposed to teach the basics of writing but felt a need for this, while the students felt that it was a waste of time to learn something in high sehool (such as the five-paragraph essay) that was not acceptable at university. The two specific areas that caused the greatest frustration for the students and professors were the students' persistence in writing within the five-paragraph essay structure and their lack of disciplinary awareness. However, if students are viewed as novices learning a new discourse, it repositions the perception of students being 
inadequately prepared for university and allows professors to see them as newcomers to a discourse community who learn through their mistakes.

In recognition of the transition that students experience in coming to university, it may be beneficial for the development of students' writing competence if they are offered some means for easing them through this transition. This study suggests that the firstyear seminar appears to be one of the more effective ways to ease the transition. Both professors and students supported first-year seminars as an opportunity for students to be in a smaller learning environment where they have more communication with their professor, have increased writing opportunities, and receive more constructive feedback on their assignments. At the very least, the hardships of the transition from high school to university needs to be more fully recognized by professors, in order for them to adjust their expectations for their students, who are after all only beginners in a new world.

\section{Limitations and Contributions to the Field}

This study has several limitations. First, there are three methodological limitations that I identify in this study. The first limitation of the study is the limited occasions and time frame in which the student participants were interviewed (two interviews over a one-month period). The second limitation is that assignment sheets did not accompany students' written assignments and, thus, I did not have an opportunity to analyze them along with the students' writing samples. This prevented me from comparing what the students wrote with what they were asked to write, and what they thought they were asked to write with what professors had intended to ask, which might have revealed additional information on the effectiveness of written communication between professors and students. In future studies, assignment sheets need to be included in the pool of 
written artefacts collected for the analysis. The third limitation is that not all pairs of students' papers came from similar courses, which did not allow me to perceive the impact of gaining disciplinary knowledge on their writing competence. In future studies, students' papers should come from similar courses in order to analyze the effect of disciplinary discourse familiarity on their writing competence.

Regardless of these limitations, the present study does add valuable knowledge to the field of research into students' perceptions of their writing needs at university. First, the study has revealed that students do value writing at university, want it to be meaningful, and perceive that they learn from clear assignment expectations and constructive feedback on the assignment. Second, the study has indicated that a communication gap appears to exist between professors and their students, as professors are often using discipline-specific discourse in their assignment instructions that students are not yet familiar with. Third, the study has shown that students may be able to expand their repertoire of writing styles and express creativity in their academic writing by gaining genre awareness, albeit without being able to consciously account for this process, and fourth, the analysis of interviews and written artefacts has demonstrated that students' ability to attain a specific goal is tied to their perception of being able to attain that goal. All of the above findings may be useful to professors and writing services administrators for the purpose of helping students to increase their writing competence.

\section{Directions for Future Research}

I propose the following two directions for future research. First is to extend this study with a longer time frame in which to conduct the study such as two full academic years in order to gain a larger and more complete sample of students' writing, professors' 
assignment instructions and feedback, and classroom experience to observe what (if any) changes occur over time. Second, further research on how high self-efficacy can hinder learning should be conducted because the existing research on this topic has revealed that students who are overly confident in their prior knowledge and have high self-efficacy beliefs may not be interested in learning new ideas. The research in this area is limited and requires close attention.

\section{Reflections}

In reflecting on this study, it seems apparent to me that in order for students to engage with writing to help them think and to produce writing that reflects their thinking, students need to become aware of the options for presenting their ideas. Professors may be able to help them with this awareness by "articulating what [they] ... expect and why [they] ... expect it" (Paré, 2007, p.8), and students need to accomplish their assigned tasks in a context that they perceive as relevant. Without this understanding, I fear that student writing at university may continue to wreak havoc on the hordes of first-year students and their professors.

In terms of personal impact, by returning to university after many years in the workplace and challenging myself to gain some knowledge in a new discipline of study, I was reminded that one must often come to the end before being able to recognize what one learned. As Steve Jobs (2005), CEO of Apple Computer, said during a convocation speech that was posted on www.youtube.com, "You can't connect the dots looking forward, you can only connect them looking backwards." Although I am still waiting for the dots to connect, I have recognized two important aspects of my learning experience from this year. The first has been very humbling. I have learned about the essential 
situatedness of genres from my experience as a student. Just because an individual has an education and is highly conversant in a native language, it is hardly possible to expect that individual to be able to express herself in any genre. Rather, it is about knowing the contextualized (or discipline-specific) language that facilitates effective communication. The second important aspect of my learning experience extends beyond the specifics of this study and writing this thesis, to the more global concept of writing that I have acquired since returning to university this year. That is, I have been significantly enlightened on the power of writing as a means for thinking. My newly acquired knowledge can best be expressed using the words from Yale University's guidelines for undergraduate studies: "To suppose that anyone who cannot write clearly can think clearly, is an illusion: words are the most basic tools of thought" (as cited in Strachan, 2008, p. 23). 


\section{References}

Artemeva, N. (2005). A time to speak, a time to act: A rhetorical genre analysis of a novice engineer's calculated risk taking. Journal of Business and Technical Communication, 19, 389-421.

Bakhtin, M. M. (1986). The problem of speech genres. In C. Emerson \& M. Holquist (Eds.), V. W. McGee (Trans.), Speech genres and other late essays (pp. 60-102). Austin, TX: University of Texas Press.

Ballard, B. \& Clanchy, J. (1988). Literacy in the university: An anthropological approach. In G. Taylor, B. Ballard, V. Beasley, H. Bock, J. Clanchy, \& P. Nightingale (Eds.), Literacy by degrees (pp.7-23). Milton-Keynes, England: Open University Press.

Bandura, A. (1977). Self-efficacy: Toward a unifying theory of behavioral change. Psychological Review, 84, 191-215.

Bandura, A. (1986). Social foundations of thought and action: A social-cognitive theory. Englewood Cliffs, NJ: Prentice-Hall.

Bandura, A. (1997). Self-efficacy: The exercise of control. New York: W.H. Freeman and Company.

Bandura, A. (2001). Social Cognitive Theory: An agentic perspective. Annual Review Psychology, 52, 1-26.

Bazerman, C. (1994). Systems of genres and the enactment of social intentions. In A. Freedman \& P. Medway (Eds.) Genre and the new rhetoric (pp. 79-101). London: Taylor \& Francis. 
Bazerman, C. (1997). The life of genres, the life in the classroom. In W. Bishop \& H. Ostrom (Eds.), Genres and writing: Issues, arguments, alternatives (pp. 19-26). Portsmouth, NH: Boynton/Cook.

Bazerman, C. (2004). Intertextuality: How texts rely on other texts. In C. Bazerman \& P. Prior (Eds.), What writing does and how it does it: An introduction to analyzing texts and textual practices (pp. 83-96). Mahwah, NJ: Lawrence Erlbaum.

Bereiter, C. \& Scardamalia, M. (1983). Does learning to write have to be so difficult? In A. Freedman, I. Pringle \& J. Yalden (Eds.), Learning to write: First language/second language (pp. 20-33). New York: Longman.

Bizzell, P. (1986). What happens when basic writers come to college? College Composition and Communication, 37, 294-301.

Brannon, L. (1995). (Dis)Missing compulsory first-year composition. In J. Petragila (Ed.), Reconceiving writing, rethinking writing instruction (pp. 239-248). Mahwah, NJ: Lawrence Erlbaum.

Britton, J. (1975). The development of writing abilities (11-18). Urbana, IL: National Council of Teachers of English.

Bruffee, K, (1984). Collaborative learning and the "Conversation of Mankind." College English, 46, 635-652.

Charmaz, K. (2006). Constructing grounded theory: A practical guide through qualitative analysis. London: Sage.

Coe, R. (1994). Teaching genre as process. In A. Freedman \& P. Medway (Eds.), Learning and teaching genre (pp. 157-165). Portsmouth, NH: Boynton/Cook. Cooper, M. \& Holzman, M. (1989). Writing as social action. Portsmouth, NH: 
Boynton/Cook.

Creswell, J. (1997). Qualitative inquiry and research design: Choosing among five traditions. London: Sage.

Devitt, A. (2004). Writing genres. Carbondale, IL: Southern Illinois University Press.

Dias, P., Freedman, A., Medway, P, \& Paré, A. (1999). Worlds Apart: Acting and writing in academic and workplace contexts. Mahwah, NJ: Lawrence Erlbaum.

Downs, D. \& Wardle, E. (2007). Teaching about writing, righting misconceptions: (Re)Envisioning "First-Year Composition" as "Introduction to Writing Studies." College Composition and Communication, 58, 552-584.

Elbow, P. (1973). Writing without teachers (2nd ed.). New York: Oxford University Press.

Elbow, P. (1991). Reflections on academic discourse: How it relates to freshmen and colleagues. College English, 53, 135-155.

Emig, J. (1971). The composing processes of twelfth graders. Urbana, IL: National Council of Teachers of English.

Fahnestock, J. (1993). Genre and rhetorical craft. Research in the Teaching of English, $27,265-271$.

Faigley, L. (1986). Competing theories of process: A critique and a proposal. College English, 48, 527-542.

Freedman, A. (1993). Show and tell? The role of explicit teaching in the learning of new genres. Research in the teaching of English, 27, 222-251.

Freedman, A. \& Medway, P. (1994). Introduction: New visions of genre and their implications for education. In A. Freedman \& P. Medway (Eds.), Learning and 
teaching genre (pp. 1-22). Portsmouth, NH: Boynton/Cook

Freedman, A. \& Pringle, I. (1980). Epilogue: Reinventing the rhetorical tradition. In A. Freedman \& I. Pringle (Eds.), Reinventing the rhetorical tradition (pp. 173-185). Conway, AR: L \& S Books.

Geisler, C. (2004). Analyzing streams of language: Twelve steps of the systematic coding of text, talk, and other verbal data. New York: Pearson Education.

Giltrow, J. (2002). Academic writing: Writing and reading in the disciplines $\left(3^{\mathrm{rd}} \mathrm{ed}.\right)$. Peterborough, ON: Broadview Press.

Hairston, M. (1982). The winds of change: Thomas Kuhn and the revolution in the teaching of writing. College Composition and Communication, 33 (1), 76-88.

Horowitz, E. K. (1987). Student beliefs about language learning. In A. Wenden \& J. Rubin (Eds.), Learner strategies in language learning (pp. 119-129). Englewood Cliffs, NJ: Prentice Hall.

Hounsell, D. (1988). Towards an anatomy of academic discourse: Meaning and context in the undergraduate essay. In R. Säljö (Ed.), The written world: Studies in literate thought and action (pp. 161-177). Berlin: Springer Verlag.

Hunt, R. (1993). Texts, textoids and utterances: Writing and reading for meaning, in and out of classrooms. In S. Straw \& D. Dogdan (Eds.), Constructive reading: Teaching

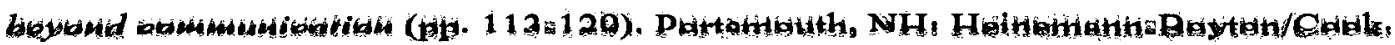

Jobs, S. (2005). Steve Jobs Stanford Commencement Speech 2005. YouTube, retrieved July 15,2009 , from http://www.youtube.com/watch?v=D1R-jKKp3NA.

Kinneavy, J. (1971). A theory of discourse. Englewood Cliffs, NJ: Prentice-Hall. 
Knoch, U. (2009). Diagnostic assessment of writing: A comparison of two rating scales. Language Testing, 26, 275-304.

Krause, K. (2001). The university essay writing experience: A pathway for academic integration during transition. Higher Education Research and Development, 20, 148168.

Lave, J. \&Wenger, E. (1991). Situated learning: Legitimate peripheral participation. Cambridge: Cambridge University Press.

Lea, M. \& Street, B. (1998). Student writing in higher education: An academic literacies approach. Studies in Higher Education, 23, 157-170.

Lincoln, Y.S., \& Guba, E.G. (1985). Naturalistic inquiry. Beverly Hills: Sage.

Linnenbrink, E. \& Pintrich, P. (2003). The role of self-efficacy beliefs in student engagement and learning in the classroom. Reading and Writing Quarterly, 19, 119137.

McCarthy, L. P., \& Fishman, S. M. (1991). Boundary conversations: Conflicting ways of knowing in philosophy and interdisciplinary research. Research in the Teaching of English, 25, 419-468.

McCune, V. (2004). Development of first-year students' conceptions of essay writing. Higher Education 47; 257-282.

Miller, C. (1984). Genre as social action. Quarterly Journal of Speech, 70, 151167.

Miller, C. (1994). Rhetorical community: The cultural basis of genre. In A. Freedman \& P. Medway (Eds.), Genre and the new rhetoric (pp. 67-78). London: Taylor \& Francis. 
Moffet, J. (1968). Teaching the universe of discourse. Boston: Houghton Mifflin.

Morris. K. (2000) The service myth: Why freshman composition doesn't serve "Us" or "Them". In R. Wallace, A. Jackson, \& S. Lewis Wallace (Eds.), Reforming college composition: Writing the wrongs (pp. 113-122). Westport, CT: Greenwood Press.

Nystrand, M. (1985). Learning to write by talking about writing: A summary of research on intensive peer review in expository writing instruction at the University of Wisconsin-Madison. Madison, WI: University of Madison Wisconsin.

Pajares, F. \& Schunk, D.H. (2001). Self-beliefs and school success: Self-efficacy, selfconcept, and school achievement. In R. J. Riding \& S. G. Rayner (Eds.), International perspectives on individual differences: Vol 2. Self-perception (pp. 239-266). London: Ablex.

Pajares, F. \& Schunk, D.H. (2005). Self-efficacy and self-concept beliefs: Jointly contributing to the quality of human life. In H. Marsh, R. Craven, \& D. McInerney (Eds.), International advances in self research, (Vol. 2, pp. 95-121). Greenwich, CT: Information Age.

Pajares, F. \& Valiante, G. (2006). Self-efficacy beliefs and motivation in writing development. In C. MacArthur, S. Graham, \& J. Fitzgerald (Eds.), Handbook of writing research (pp. 158-170). New York: The Guilford Press.

Paré, A. (1994). Toward a post-process pedagogy; or what's theory got to do with it? English Quarterly, 26(2), 4-9.

Paré, A. (2007, May). What we know about writing, and why it matters. Retrieved 
September 21, 2009, http://etc.dal.ca/ojs211/index.php?journal=C2\&page=article\&op=view\&path[]=66\&p $\operatorname{ath}[]=33$

Petraglia, J. (1995). Writing as an unnatural act. In J. Petraglia (Ed.), Reconceiving writing, rethinking writing instruction (pp. 79-100). Mahwah, NJ: Lawrence Erlbaum. Pintrich, P.R. (1999). The role of motivation in promoting and sustaining self-regulated learning, International Journal of Educational Research, 31, 459-470.

Prior, P. (2004). Tracing Process: How texts come into being. In. C. Bazerman \& P. Prior (Eds.), What writing does and how it does it: An introduction to analyzing texts and textual practices (pp.167-200). Mahwah, NJ: Lawrence Erlbaum.

Reither, J. (1985). Writing and knowing: Toward redefining the writing process. College English, 47, 620-628.

Reither, J. \& Vipond, D. (1989). Writing as collaboration. College English, 5, 855-867.

Roe, S. \& den Ouden, P. (2003). Preface. In Designs for disciplines: An introduction to academic writing. (pp. xiii-xx). Toronto: Canadian Scholars Press.

Rose, D., Gray, B., \& Cowey, W. (1999). Scaffolding reading and writing for indigenous children in school. In P. Wignell (Ed.), Double Power: English literacy in indigenous schooling (pp. 1-39). Melbourne: Languages Australia.

Russell, D. (1992). American origins of the writing-across-the-curriculum movement. In Herrington \& C. Moran (Eds.), Writing, teaching, and learning in the disciplines (pp. 22-42). New York: The Modern Language Association of America. 
Russell, D. (1997). Rethinking genre in school and society: An activity theory analysis. Written Communication, 14, 504-554.

Schunk, D.H. (2003). Self-efficacy for reading and writing: Influence of modeling, goal setting, and self-evaluation. Reading and Writing Quarterly, 19, 159-172.

Shaughnessy, M. (1977). Errors and expectations: A guide for the teacher of basic writing. New York: Oxford University Press.

Skaalvik, E. (1997). Issues in research on self-concept. In M. Maehr \& P. Pintrich (Eds.), Advances in motivation and achievement (Vol. 10, pp. 51-97). Greenwich, CT: JAI Press.

Sommers, N. \& Saltz, L. (2004). The novice as expert: Writing the freshman year. College Composition and Communication, 56, 124-149.

Strachan, W. (2008). Writing Intensive: Becoming W-Faculty in a new writing curriculum. Logan, UT: State University Press.

Strauss, A. \& Corbin, J. (1990). Basics of qualitative research: Grounded theory procedures and techniques. Newbury Park, CA: SAGE.

Swales, J. (1988). Discourse communities, genres and English as an international language. World Englishes, 7, 211-220.

Swales, J. (1990). Genre Analysis: English in academic and research settings. Cambridge: Cambridge University Press.

Swales, J. (1998). Other floors, other voices: A textography of a small university building. Mahwah, NJ: Lawrence Erlbaum.

Vygotsky, L. S. (1978). Mind in society: The development of higher psychological processes. Cambridge, MA: Harvard University Press. 
Wallace. R \& Wallace S. (2000). Readerless writers: College compositions' misreading and misteaching of entering students. In R. Wallace, A. Jackson, \& S. Lewis Wallace (Eds.), Reforming college composition: Writing the wrongs (pp. 79-98). Westport, CT: Greenwood Press.

Wardle, E. (2007). Understanding "Transfer" from FTC: Preliminary results of a longitudinal study. Writing Program Administration, 31, 65-85.

Weaver, M.R. (2006). 'Do students value feedback? Student perceptions of tutors' written responses'. Assessment \& Evaluation in Higher Education, 31, 379-394.

White, E. M. (1985). Teaching and assessing writing. San Francisco: Jossey-Bass.

Williams, J. \& Colomb, G. (1993). The case for explicit teaching: Why what you don't know won't help you. Research in the Teaching of English, 27, 252-264.

Wood, D., Bruner, J., \& Ross, G. (1976). The role of tutoring in problem-solving. Journal of Child Psychology and Child Psychiatry, 17, 89-100.

Young, A. \& Fulwiler, T. (1986). Introduction. In A. Young \& T. Fulwiler (Eds.), Writing across the disciplines: Research into practice (pp. 1-3). Portsmouth, NH: Boyton/Cook. 


\section{Appendices}

\section{Appendix A: Interview Questions for Students}

\section{Part 1}

1. What is your language background?

2. Please describe your high school academic performance.

3. Family background:

- Education levels of parents?

- Jobs of parents?

- Parental support for university attendance?

4. What are your extracurricular interests

- Are you an active reader?

5. What academic program are you in?

- Tell me about your interest in the program

Part 2

1. Do you think academic writing is an important skill/ability for students to have and/or develop during their time at university? Why or why not?

2. Do you think writing is an important skill/ability for students to develop in all diseiplines of study or only specific disciplines? Why or why not?

3. What do you think are the different writing challenges that students face at different stages of their academic studies? For example, in your first-year did you have different writing challenges than you do today?

4. What are some of the biggest writing challenges you have experienced when completing various writing assignments during your time at university?

a) What were these assignments?

b) What are some of the strategies and/or services you have made use of to address these challenges?

5. What role do you think professors and teaching assistants have in helping you develop your academic writing skills?

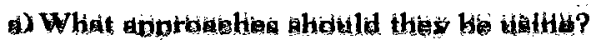

6. What student services should be available to help students in developing their academic writing skills?

a) What approaches should they be using?

7. What role do you think university administration has in helping you to develop your academic writing skills? 
a) What approaches should they be using?

8. Have you participated in any programs at University to help students develop their academic writing skills?

a) What do these programs do?

b) What was helpful about these programs?

c) What was unhelpful about these programs?

9. If you participated in a fysm, what would you say the benefits of this were?

10. If you were in Arts One last year, what would you say the benefits of this were?

\section{Part 3}

11. What do you do when you get a marked essay returned to you?

12. What kinds of comments are typical on your returned essay?

13. What do you do with this feedback?

14. Is feedback helpful?

15. What would you change in this feedback process?

16. What skills or abilities did you learn in first-year, that you now use? 


\section{Appendix B: Interview Questions for Professors}

1. In your opinion, what is the importance of developing writing skills, while at university?

2. What is the role that academic writing plays in first-year courses?

3. In your opinion, is it more important for students to develop writing skills in all disciplines of study or only specific disciplines?

4. What writing challenges do students in first-year face as opposed to later in their academic studies?

5. What are some of the biggest writing challenges you have seen in first-year students' writing?

a) How do you go about addressing such writing challenges?

b) How is this different than second or third year writing challenges?

c) How do you think these writing challenges could affect students' abilities to be successful at university?

6. What role do you think professors and teaching assistants have in helping students develop their academic writing skills?

a) If they should be active in helping students develop their academic writing skills, what methods/approaches should they be using?

b) What role do you think university student services should play in helping students develop their academic skills?

- What methods/approaches should they be using?

c) What role do you think university administration has in helping students develop their academic writing skills?

- What methods/approaches should they be using?

7. What is Carleton's philosophy of the first-year seminar?

a) If you teach in both first-year seminars and others courses, how would you describe the differences from a teaching/learning perspective?

b) If you teach in Arts One and outside of this program, how would you describe the

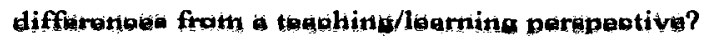

8. I have heard the following from professors, teaching assistants, etc, "I am marking these students' papers and they have no idea how to write! How did they ever get into university?"

a) What is your reaction to such a statement?

b) If this is the case, why do you think it's happening? 
Appendix D: DELNA Rating Scale

Appendix 1: Abridged DELNA scale

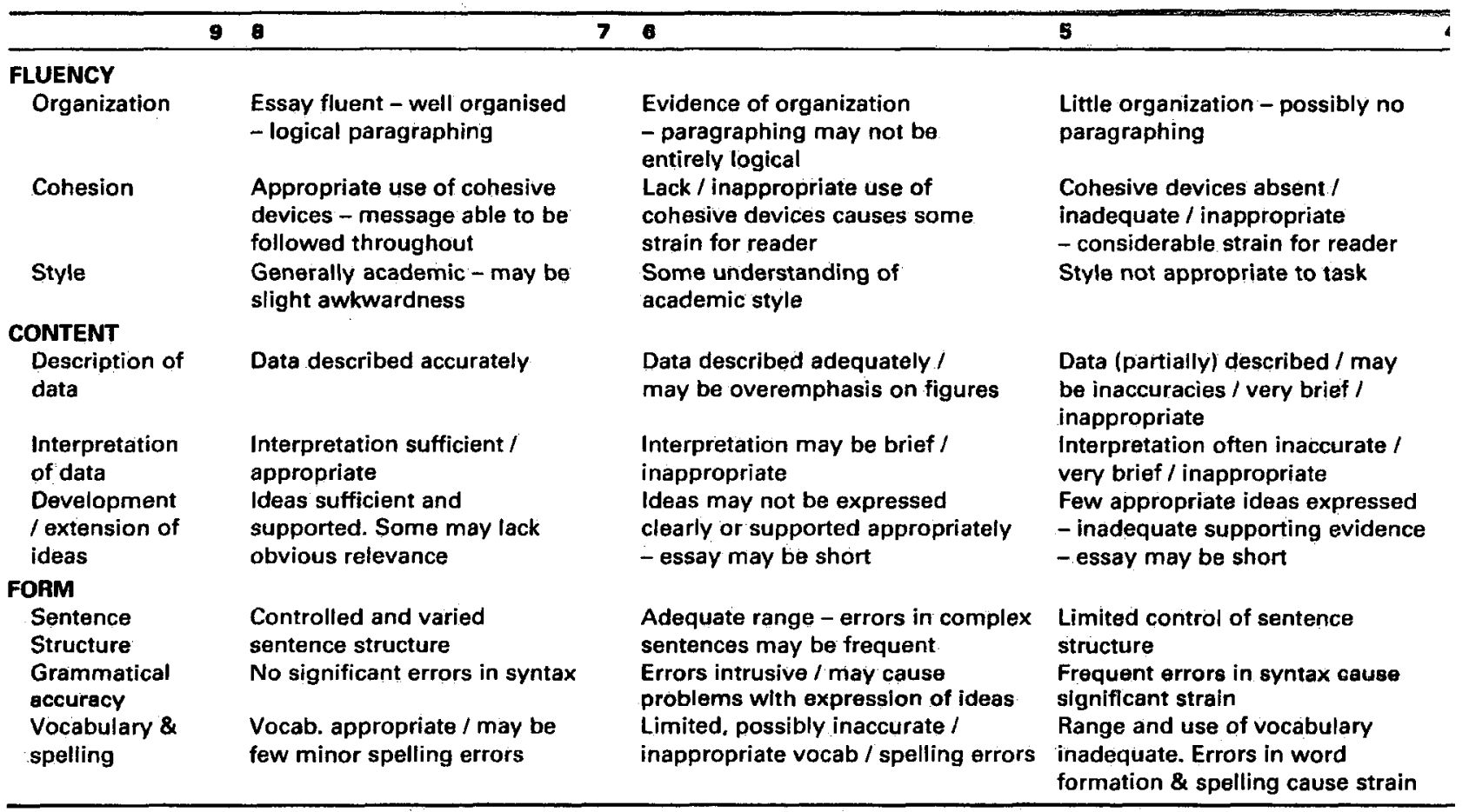

Note: From " Diagnostic Assessment of Writing: A comparison of two rating scales", by U. Knoch, 2009, Language Training, 26(2), p.275-304.

Copyright 2009 by Copyright Holder. Reprinted with permission. 


\section{Appendix E: Copyright Permission}

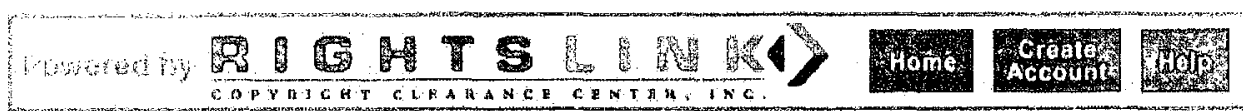

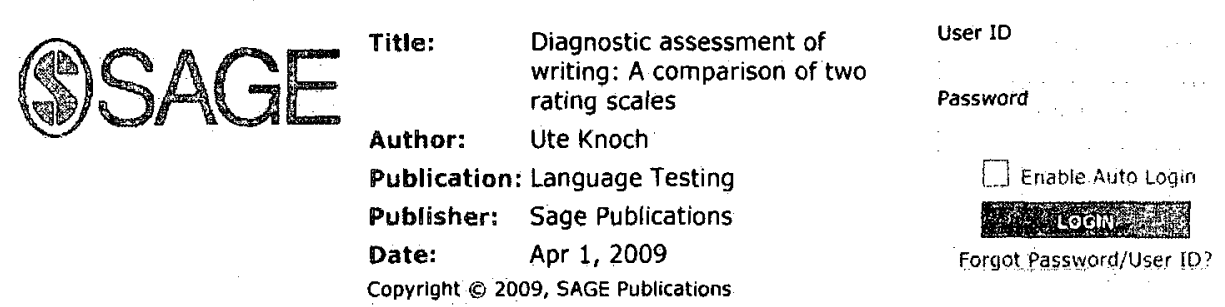

Gratis

Permission is granted at no cost for sole use in a Master's Thesis and/or Doctoral Dissertation. Additional permission is also granted for the selection to be included in the printing of said scholarly work as part of UMI's "Books on Demand" program. For any further usage or publication, please contact the publisher. 


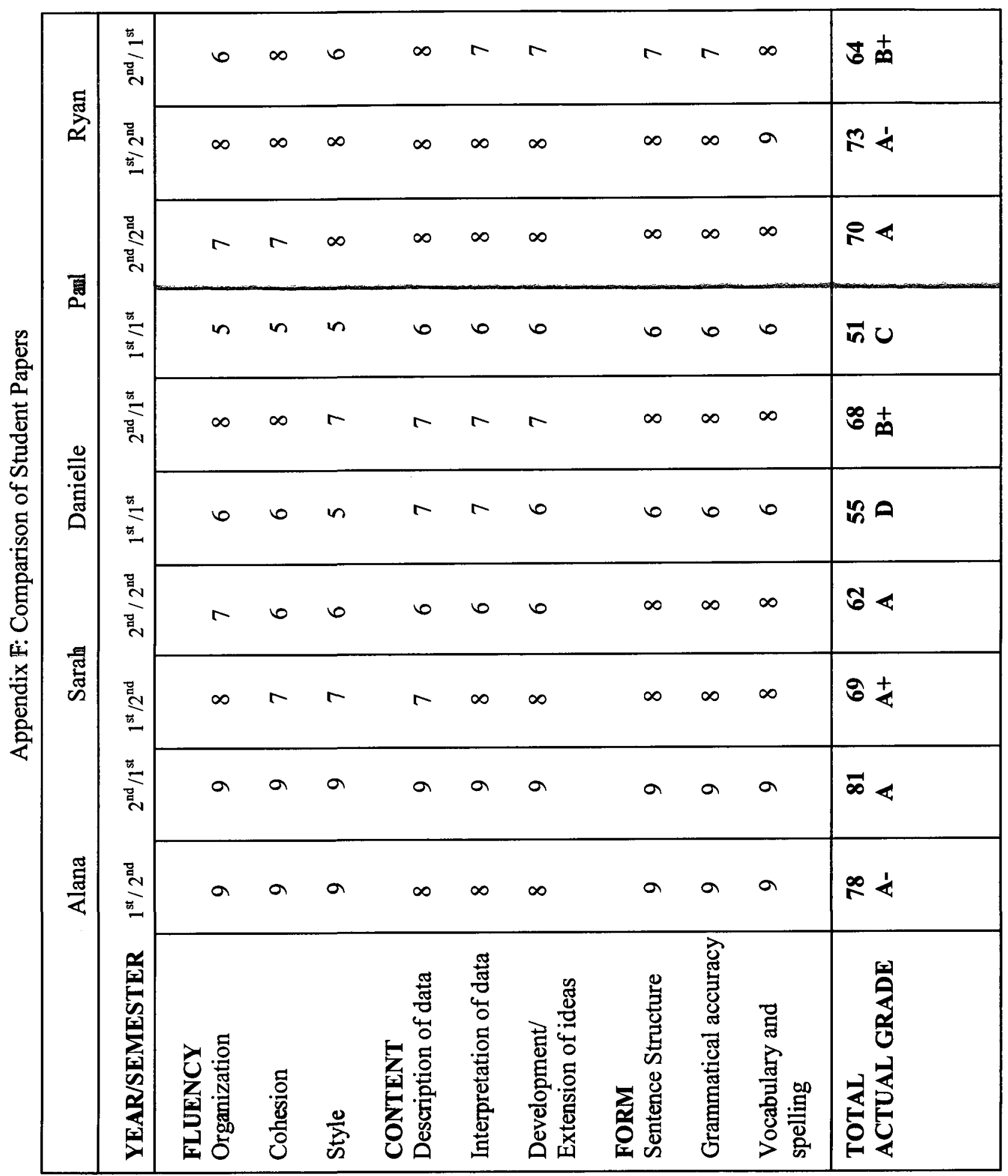


ฮ

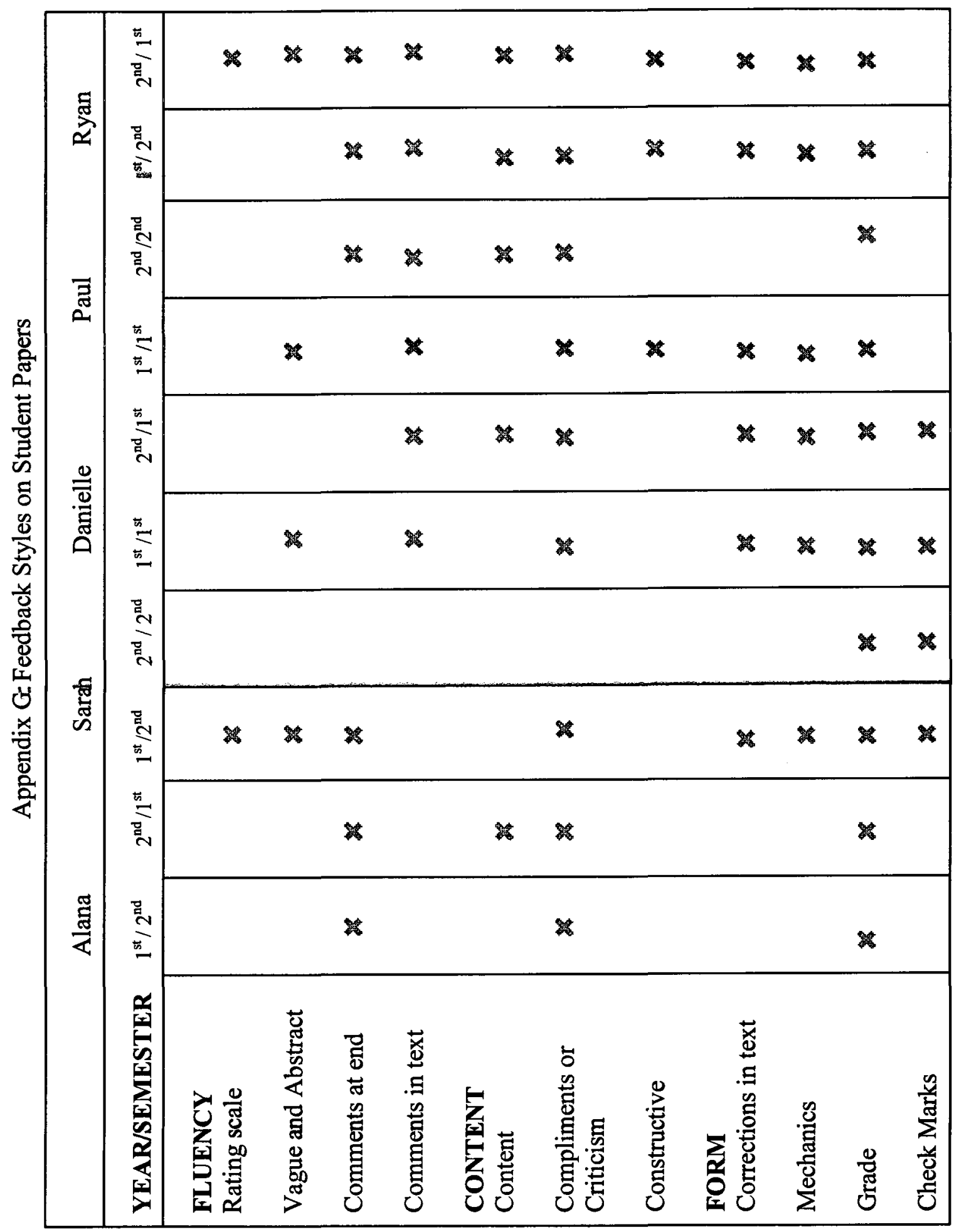

